\title{
The Diagnostic and Prognostic Value of a Liquid Biopsy for Esophageal Cancer: A Systematic Review and Meta-Analysis
}

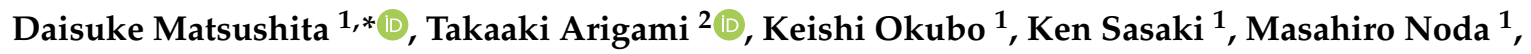 \\ Yoshiaki Kita ${ }^{1}$, Shinichiro Mori ${ }^{1}$, Yoshikazu Uenosono ${ }^{3}$, Takao Ohtsuka ${ }^{1}$ and Shoji Natsugoe ${ }^{4}$ \\ 1 Department of Digestive Surgery, Breast and Thyroid Surgery, Kagoshima University Graduate School of \\ Medical and Dental Sciences, Kagoshima 890-8520, Japan; ok0627@m2.kufm.kagoshima-u.ac.jp (K.O.); \\ k-sasaki@m.kufm.kagoshima-u.ac.jp (K.S.); nodamasahiro69@kufm.kagoshima-u.ac.jp (M.N.); \\ north-y@m.kufm.kagoshima-u.ac.jp (Y.K.); morishin@m3.kufm.kagoshima-u.ac.jp (S.M.); \\ takao-o@kufm.kagoshima-u.ac.jp (T.O.) \\ 2 Department of Onco-biological Surgery, Kagoshima University Graduate School of Medical and Dental \\ Sciences, Kagoshima 890-8520, Japan; arigami@m.kufm.kagoshima-u.ac.jp \\ 3 Department of Surgery, Jiaikai Imamura General Hospital, Kagoshima 890-0064, Japan; \\ uenosono@m3.kufm.kagoshima-u.ac.jp \\ 4 Department of Surgery, Gyokushoukai Kajiki Onsen Hospital, Aira 899-5241, Japan; \\ s-natsugoe@gyokushoukai.com \\ * Correspondence: m7762@m2.kufm.kagoshima-u.ac.jp; Tel.: +81-99-275-5361; Fax: +81-99-265-7426
}

Received: 9 September 2020; Accepted: 18 October 2020; Published: 21 October 2020

Simple Summary: The "liquid biopsy" is a novel concept for detecting circulating biomarkers in the peripheral blood of patients with various cancers, including esophageal cancer. There are two main methods to identify circulating cancer related biomarkers such as morphological techniques or molecular biological techniques. There are some differences in the sensitivity and specificity for detecting circulating tumor cells (CTCs) or circulating markers between each method. Although it is still challenging to determine strong candidates for early diagnosis and predicting prognosis in patients with esophageal cancer, our meta-analysis might be a milestone for the future development of liquid biopsies in use with esophageal cancer.

\begin{abstract}
Esophageal cancer is among the most aggressive diseases, and circulating tumor cells (CTCs) have been recognized as novel biomarkers for various cancers over the past two decades, including esophageal cancer. CTCs might provide crucial clinical information for predicting cancer prognosis, monitoring therapeutic responses or recurrences, or elucidating the mechanism of metastasis. The isolation of CTCs is among the applications of a "liquid biopsy". There are various technologies for liquid biopsies, and they are classified into two main methods: cytometric or non-cytometric techniques. Here, we review a total of 57 eligible articles to summarize various technologies for the use of a liquid biopsy in esophageal cancer and perform a meta-analysis to assess the clinical utility of liquid biopsies as a prognostic and diagnostic biomarker technique. For prognostic evaluation, the pooled hazard ratio in the cytometric assay is relatively higher than that of the non-cytometric assay. On the other hand, a combination of multiple molecules, using a non-cytometric assay, might be a favorable biomarker technique for the early diagnosis of esophageal cancer. Although determining strong evidence for a biomarker by using a liquid biopsy is still challenging, our meta-analysis might be a milestone for the future development of liquid biopsies in use with esophageal cancer.
\end{abstract}

Keywords: liquid biopsy; circulating tumor cell; diagnostic value; prognostic value; esophageal cancer 


\section{Introduction}

Esophageal cancer (EC) is the sixth leading cause of cancer-related deaths worldwide, and it can be classified into two main histological subtypes: Esophageal adenocarcinoma (EAC) and esophageal squamous cell carcinoma (ESCC). Almost all EACs develop in the lower third of the esophagus and originate from the Barrett mucosa, and ESCC occurs in the upper two-thirds of the esophagus. Approximately $80 \%$ of ESCC cases occur in central and southeastern Asia, while the incidence of EAC is high in northern and western Europe, North America, and Oceania [1]. Overall survival (OS) is similar for ESCC and EAC. Although clinical diagnostic instruments such as endoscopy, computed tomography (CT), and positron emission tomography (PET) have been developed, over sixty percent of patients are diagnosed with EC with advanced progression of the disease because of their poor symptoms in the early stage [2]. Patients with EC have poorer prognosis than those with other cancers, and even if they receive curative surgical resection, some experience early recurrence or metastasis [3]. CT and PET are still standard imaging examinations for the diagnosis and monitoring of cancers, while the limitation of low sensitivity for small lesions has been a difficult issue to detect early recurrence sites. Similarly, serum biomarkers, such as carcinoembryonic antigen (CEA) and squamous cell carcinoma antigen (SCC), have low sensitivity and specificity for early diagnosis or the detection of recurrence [4]. Therefore, a "liquid biopsy", which is a simple and non-invasive sampling of non-solid biological tissue or DNA/RNAs from peripheral blood, is needed to provide new alternative serum biomarkers for monitoring the malignant behavior of cancer.

Ashworth et al. demonstrated the presence of circulating tumor cells (CTCs) in the peripheral blood of cancer patients in 1869 [5]. CTCs shed into the peripheral blood stream via primary tumors and extravasate into distant organs to form metastases. In the last two decades, CTCs have been identified as novel biomarkers to elucidate the mechanism of spreading metastasis and the dissemination of cancer. Allard et al. suggested that CTC measurement using the CellSearch system (Menarini-Silicon Biosystem, Bologna, Italy) might have clinical utility for all cancers of an epithelial origin [6]. To date, many kinds of liquid biopsy technologies have been reported. The most common methods of detecting CTCs are cytometric-based fluorescence immunohistochemical staining (F-IHC) and polymerase chain reaction (PCR) methods.

Quantitative reverse transcription-PCR (qRT-PCR) is a promising technique for quantifying the copy number of mRNA of interest, such as CEA, SCC, and survivin [7-9]. Recently, due to the rapid technological advances in molecular biology, CTC analysis has moved to the next stage, which is comprehensive analysis using microarrays or next-generation sequencing (NGS) for genetic variations. These analyses can target hundreds to thousands of microRNAs (miRNAs) or cell-free DNAs/RNAs in peripheral blood with a single procedure.

On the other hand, cytometric detection technologies have been developed that enable the capture of CTCs as a single cell and visual evaluation for phenotype characterization. CTC identification relies on positive or negative selection by leukocyte depletion. The CellSearch system, the only CTC technology cleared by the US Food and Drug Administration (FDA), is among the most representative pieces of equipment for positive selection methods. The clinical utility of CellSearch to predict tumor progression and prognosis has been reported in many cancers, including breast cancer [10], colorectal cancer [11], prostate cancer [12], and ESCC [13]. Additionally, other technologies have been reported as cytological detection methods: isolation by size of epithelial tumor cells (ISET) [14], ScreenCell [15], and MetaCell [16] as size-based separation systems; magnetic cell separation system (MACS) [17], CTC-Chip [18], and IsoFlux [19] as microfluidic-based, immune-magnetic, positive selection methods; RosetteSep as a density gradient centrifugation method [20]; and also flow cytometry. Recently, the genomic analysis of CTCs using deep sequencing was reported because of advances in single-cell analysis [21,22]. According to these studies, the detection and isolation methods of CTCs or cancer-related genes were called "liquid biopsy" methods. Many studies have attempted to demonstrate the diagnostic or prognostic value of liquid biopsies in EC, and the clinical usefulness of 
liquid biopsies remains controversial. Herein, we summarize articles published about liquid biopsies in EC and discuss the potential utility of liquid biopsies in clinical use.

\section{Results}

\subsection{Literature Extraction}

We identified 804 articles as potentially relevant studies, of which a total of 57 articles were finally retrieved as eligible studies according to the above criteria for this systematic review (Figure 1). A total of 11,102 cases were involved in this study, and the median number of patients was 93 . In these studies, 37 articles were included in the prognostic meta-analysis and 28 articles provided diagnostic information. These studies were conducted in ten countries (Australia, China, France, Germany, Japan, Korea, Poland, Czech Republic, Taiwan, and the Netherlands), and different technologies were used to assess the utility of liquid biopsies.

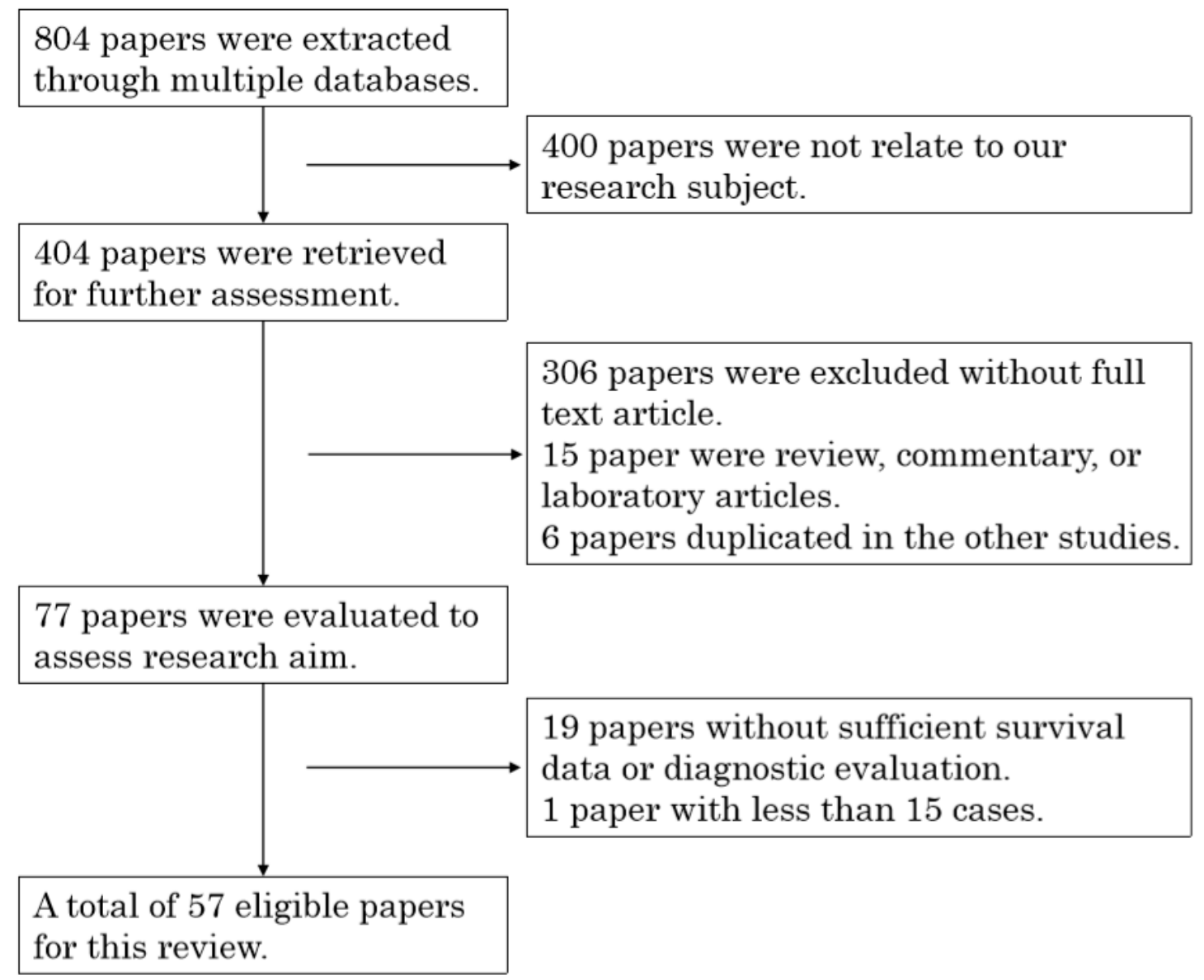

Figure 1. Selection process for literature in the meta-analysis.

\subsection{Summary of Different Technologies for Liquid Biopsy}

Currently, there are two main methods for liquid biopsies. One of them is cytological approaches to detect and isolate circulating tumor cells, and the other method involves non-cytological approaches, such as qRT-PCR, enzyme-linked immunosorbent assay (ELISA), and liquid chromatography-mass spectrometry (LC-MS) techniques to detect circulating genomic materials or metabolites from cancers. In the early 2000s, the mainstream liquid biopsy techniques were PCR for mRNAs and ELISA for proteins. A PCR assay permits the molecular detection of cancer-related mRNA expression. Moreover, qRT-PCR is a promising tool for quantifying mRNA copy numbers, and its high sensitivity is a great advantage for CTC assessment. Cytokeratin (CK), CEA, SCC, and survivin are the most common 
target genes for CTC in EC. Survivin is a member of the inhibitor of apoptosis genes and contributes to the inhibition of apoptosis in tumor progression [23]. However, several investigators have identified some limitations in the clinical use of PCR-based assays. False positive results are among the most important limitations, caused by cancer heterogeneity or the contamination of normal epithelial cells.

In the middle of the 2000s, cytological CTC detection technologies emerged, such as ISET and CellSearch, and not only identification but also the enumeration and characterization of CTCs became a secondary mainstream purpose in liquid biopsy studies. In the early stages, a strategy based on epithelial markers (epithelial cell adhesion molecules (EpCAMs) and CK) was used. Subsequently, the epithelial-mesenchymal transition (EMT) has been recognized as a promising phenomenon involved in the metastatic process of cancers. In the EMT, epithelial cancer cells lose their polarity and are shed into the peripheral blood circulation. To detect these EMT cells, numerous platforms with non-EpCAM-based technologies for CTC study have been developed around the world. In the 2010s, microfluidic-based platforms emerged, and combination analysis with next-generation sequencing technology developed the single-cell genomic characterization of CTCs to the next stage.

\subsection{Summary of Platforms for the Cytometric Isolation of CTCS}

\subsubsection{Immuno-Magnetic Technology}

The CellSearch System was introduced in 1999 and is the first and only clinically validated, FDA-cleared system for the identification, isolation, and enumeration of CTCs from peripheral blood [6]. CellSearch isolates epithelial cells from peripheral blood using anti-EpCAM antigen-coated nano-ferrofluid, and CTCs are then distinguished from leukocytes by multifluorescent immunohistochemical staining using pan-cytokeratin (CK8, CK18, and CK19) dye 4, 6-diamidino-2-phenylidole dihydrochloride (DAPI), and CD-45 using the CellSearch Epithelial Cell Kit. These CTC separation and staining processes are fully automated by the CellTracks AutoPrep System, and CTC identification and enumeration are semi-automated by the CellTracks Analyzer II fluorescence-based microscopy system. With this system, users are able to add one more FITC (Fluorescein isothiocyanate)-labeled fluorescent reagent, such as HER2/neu antibodies. Several investigators have demonstrated that CellSearch is a promising tool for clinical management in patients with EC [13,24-26].

In contrast to CellSearch, CD45-labeled magnetic beads have been used for the negative selection of CTCs by the depletion of CD45-positive leukocytes. Qiao et al. reported the clinical utility of the subtraction enrichment of CTCs using CD45-coated magnetic beads (Miltenyi Biotec, Bergisch Gladbach, Germany) and triple immunohistochemical staining (CK8/18/19, CD45, and DAPI) [27]. Moreover, Li [28] and Zhang [29] demonstrated that the isolation and characterization of CTCs by CD45 bead negative selection is able to assess the chromosome multiploidy of CEP8, suggesting clear potential in improving the management of EC in clinical practice.

Another technology based on immunomagnetic CTC capture is the magnetic cell separation system (MACS) [17]. Here, cells stained sequentially with specific biotinylated antibodies, streptavidin-fluorochrome conjugates, and biotinylated superparamagnetic beads (approximately $100 \mathrm{~nm}$ in diameter) are separated on high-gradient magnetic columns. Unlabeled cells pass through the column, while labeled cells are retained. The retained cells can be easily eluted, and these cells are finally sorted by fluorescence microscopy or flow cytometry. MACS is also the most historical platform of CTC studies and can be applied to both positive and negative selection sequencing for downstream analysis.

Although positive enrichment depending on antibody specificity ensures high cell purity, it has several pitfalls; for example, it is difficult to detach magnetic beads coated with specific antibodies, and this antibody collection has a selection bias for CTCs. On the other hand, negative selection has a much lower purity of CTC-positive enrichment [30]. 


\subsubsection{Filtration Technology}

The ISET system is among the historical CTC platforms, and the first report on it was published by Vona in 2000 [14]. Vona et al. demonstrated that ISET could isolate CTCs by size filtration using an $8 \mu \mathrm{m}$ pore size filter from the whole blood of hepatocellular carcinoma patients. This CTC collection method supports the differences in size and rigidity between CTCs and leukocytes [31].

Furthermore, many CTC studies using ISET have been reported for many cancers, including EC [32]. Several similar devices based on filtration have been developed, such as ScreenCell [15], MetaCell [16], and more. These filtration-based CTC capture methods are simple and offer time-cost saving protocols compared to other CTC platforms. The filtration platforms are not dependent on EpCAM expression and can capture circulating epithelial-mesenchymal tumor (EMT) cells. Moreover, filtration devices can isolate CTCs, not only as single cells but also as circulating tumor microemboli (CTM). These results allow us to perform a more in-depth genomic analysis of CTCs to help shed light on the mechanisms of cancer progression.

\subsubsection{Microfluidic Technology}

The CTC chip is the first microfluidic device to isolate CTCs, developed by Nagrath in 2007, and is based on laminar flow conditions with EpCAM-coated microposts. The CTC chip has successfully identified CTCs in the peripheral blood of patients with metastatic lung, prostate, pancreatic, breast, and colon cancer in 115 of 116 (99\%) samples, with a range of 5-1281 CTCs per mL, and approximately $50 \%$ purity [18]. The CTC chip allowed us to apply subsequent analyses, such as a mutational study of genes of interest. Ohnaga reported that the CTC chip was able to isolate EC cell lines spiked in whole blood, and that its recovery rate was over 70\% [33]. Following the CTC chip, many kinds of microfluidic platforms have been developed, such as ClearCell FX, based on size, deformability, and inertia separation [34]; CTC-iChip, based on positive and negative enrichment with size-based separation [35]; IsoFlux, based on automated continuous flow with EpCAM beads [19]; magnetic sifter, based on vertical flow configuration [36]; and vortex, based on inertial microfluidics and laminar microscale vortices without a red blood cells (RBC) lysis buffer [31].

In a study of esophageal cancer, two automated commercial systems have been reported. Among these is the ClearCell FX1 system, using the CTChip. This microfluidic biochip isolates CTCs based on their size, deformability, and inertia relative to other blood components using the inherent Dean vortex flows present in curvilinear channels after RBC lysis is performed. Through this process, blood cells separate and distribute themselves within the channels of the CTChip, with larger cells collecting along the inner wall and the smaller cells presenting as more separated from it. The other is the IsoFlux platform, which includes four fluidic reservoirs (sample inlet, isolation zone, waste well, and recovery tube) interconnected by microfluidic channels. Before applying samples to IsoFlux, a coupling step with immunomagnetic beads coated with anti-EpCAM antibodies is required. Samples conjugated with magnetic beads flow through the channels at a continuous flow, and each sample runs through the channel for $45 \mathrm{~min}$. The isolated target cells are recovered from the isolation zone disk, which consists of a removable, low-adherence polymer disk below a magnet, and these cells are removed into a microfuge tube for further processing.

Another microfluidic platform is the fluid-assisted separation technique (FAST) disc. The FAST disc is a centrifugal and size-selective microfluidic system. This method requires no sample treatment step and the disk, passivated with bovine serum albumin, is able to isolate CTCs on the membrane by the original spin program. Finally, multi-immunofluorescent staining is performed on the FAST disc to identify CTCs [37]. 


\subsection{Summary of Platforms for the Non-Cytometric Isolation of CTCS}

\subsubsection{ELISA}

ELISA is among the most common and historical protein measurement methods and has been used to measure circulating antigens and antibodies in peripheral blood [38]. Several authors have reported the clinical utility of ELISA in detect circulating cancer-related molecules. In 2005, Nozoe reported that a decreased CD4/CD8 ratio, as well as increased CD8 and decreased CD4 levels in peripheral blood, could predict worse prognosis in patients with ESCCs [39]. In 2008, Kimura demonstrated that preoperative circulating VEGF-C levels predicted recurrence in patients with EC [40].

Recently, immune checkpoint inhibitors (ICIs), such as anti-PD-1 (Programmed cell Death 1) and anti-CTLA 4 (cytotoxic T-lymphocyte-associated protein 4), have emerged as new targets for cancer treatment, and many clinical studies have been conducted. Further ELISA studies on circulating ICIs, including EC patients, are required to develop this field [41].

\subsubsection{RT-PCR}

The PCR-based analysis is among the most common and simple techniques to identify the amplification or depletion of circulating cancer-related markers. In many cancers, including EC, the prognostic and diagnostic value of CTCs using PCR-based analysis has been reported. The greatest advantage of the PCR assay is its high sensitivity for detecting targeted circulating molecules, and we have previously investigated the clinical importance of circulating carcinoembryonic antigen (CEA) mRNA. The sensitivity, specificity, positive predictive value, and negative predictive value of CEA mRNA were higher than serum CEA or SCC, and the examination of CEA mRNA in peripheral blood during follow-up is useful for the early detection of occult recurrence [42]. The other major targets of circulating mRNA are CK19, SCC, and survivin [4]. Survivin is a member of the apoptosis inhibitor gene family and plays an important role in tumor progression. Survivin controls tumor apoptosis, promotes proliferation, and enhances angiogenesis via a vascular endothelial growth factor signaling pathway [43]. Moreover, Hoffmann demonstrated that the elevation of survivin levels after curative resection is associated with shorter OS in EC [44]. However, several investigators have noticed some limitations for PCR-based CTC analysis because the false positive results may have occurred because of the non-specific expression of targeted genes in normal and epidermal cells [45]. Therefore, further studies are needed to resolve this problem.

\subsubsection{Non-Coding RNAs}

MicroRNAs (miRNAs) are small, non-coding single-stranded RNAs that range from 20 to 25 nucleotides in length. MicroRNAs are able to exist stably in cell-free environments such as urine and peripheral blood. The first report that investigated the potential of miRNAs as diagnostic markers was published in 2008 [46]. There are abundant studies on circulating miRNAs in many cancers, including EC, and several researchers have combined several miRNAs to improve their diagnostic value [47-68]. Currently, molecular science technology has been constantly evolving, and microarray and NGS platforms have made it possible to perform comprehensive gene analysis using liquid biopsies $[53,59,60,65,66,68,69]$. Many studies have investigated the clinical utility of miRNAs as diagnostic or prognostic indicators in EC patients; however, these results are still controversial due to the heterogeneity of each study caused by differences in the backgrounds and detection methods.

Long non-coding RNAs (lncRNAs) are defined as transcripts with lengths exceeding 200 nucleotides that are not translated into proteins [70]. LncRNAs play crucial roles in tumor initiation, progression, and metastasis by regulating oncogenic or tumor-suppressing pathways [71]. Similar to miRNAs, several lncRNAs have been identified as potential biomarkers in many solid cancers. There are, however, only a few studies that have been reported in EC patients. Luo et al. demonstrated that the upregulation of circulating lncRNA SNHG1 has potential as a diagnostic marker and indicates poor prognosis in ESCC [63]. Llnc-POU3F3 in plasma has also been suggested as a novel 
biomarker for early ESCC diagnosis [72]. Hu reported the clinical utility of three circulating lncRNAs (Linc00152, CFLAR-AS1, and POU3F3) as predictors of early ESCC progression [73].

\subsubsection{Circulating Tumor DNA}

The presence of circulating cell-free DNA (ccfDNA) in human peripheral blood was already reported in 1948 [74], and several researchers have demonstrated that ccfDNA levels in cancer patients are elevated compared to healthy controls. In general, increased ccfDNA levels in blood correlate with unusually high cell death, linked to different pathological conditions of tumorigenesis. Such DNA fractions from tumor sites are also known as circulating tumor DNA (ctDNA). The concentration of ctDNA is extremely low, and the development of detection methods has been challenging. The simplest technique of ccfDNA quantification is concentration reading with a fluorometer. Ko demonstrated that increasing ccfDNA concentration levels during two cycles of chemotherapy can predict early disease progression and poor outcomes [75]. On the other hand, the quantification of total ccfDNA presents a risk for the contamination of non-specific ccfDNA from normal tissue, which causes poor sensitivity and specificity for the diagnosis or prediction of cancer-related outcomes. As mentioned above, new science technologies, such as NGS platforms or digital droplet PCR (ddPCR), enable ultra-sensitive analysis to detect ctDNAs and understand the characteristics of ctDNAs via somatic mutation analysis [76]. However, ccfDNA analysis has one limitation for clinical use because of the contamination from genomic DNA in the early hours after blood collection [77].

\subsubsection{LC-MS}

Metabolomics is the systemic study of endogenous small molecule compounds $(<1000 \mathrm{Da})$ in biological specimens, including blood, urine, and other tissues. Metabolomics might provide information about oncogenesis or tumorigenesis. Recently, LC-MS and nuclear magnetic resonance spectroscopy have been applied to metabolomics as novel and sensitive techniques to identify new cancer-related biomarkers. Using these platforms, several authors have demonstrated the clinical utility of metabolite combinations to detect EC in the early stages or to make differential diagnoses between high-grade dysplasia/Barrett esophagus and EC [78-80]. Thus, mass spectrometry-based analysis appears to be a powerful technique for biomarker detection; however, no universal instrument or method exists yet, and we are still in the process of metabolomics profiling to understand the interactions between metabolites, as well as other related molecular profiling [81].

This is why many investigators have used combinations of multiple metabolites as candidates for cancer diagnosis.

\subsection{Prognostic Value of CTC Identification}

In this section, we evaluate the prognostic values using forest plot analysis for the hazard ratio (HR) of each molecule for a "liquid biopsy".

\subsubsection{OS in the Cytometric Assay}

Eleven studies were enrolled for OS analysis, with a total of 854 EC patients $[13,25-27,29,32,54,75$, 82-85]. In this cohort, the average age was 63.6 years (61.5-66) and the median CTC positivity rate was $46.4 \%$ (18.0-79.7). The median CTC detection rates in stages I-II and III-IV were $20.0 \%(0.0-33.3)$ and $43.5 \%$ (8.3-69.0), respectively. The median CTC detection rates in T 1-2 and 3-4 were 28.8\% (7.5-55.6) and $36.2 \%(8.0-60.8)$, respectively (Table 1$)$.

The pooled HR for OS was $2.43(95 \% \mathrm{CI}=1.66-3.55)$, and poor OS was observed in CTC-positive patients compared to CTC-negative patients (Figure 2a). The negative selection with CD45 magnetic beads [27] appeared to exhibit the most powerful prognostic predictive value. There were no significant differences between each detection method because of the heterogeneity of this cohort $\left(I^{2}=59 \%\right.$, $p<0.01$ ) and the existence of a publication bias was visualized as a funnel plot (Figure $2 b$ ). 
Table 1. The results of liquid biopsies for prognostic evaluation in the cytometric assays.

\begin{tabular}{|c|c|c|c|c|c|c|c|c|c|c|c|c|c|c|c|c|c|}
\hline $\begin{array}{l}\text { Author Year, } \\
\text { Country }\end{array}$ & Technology & Molecules & SS & CS & $\begin{array}{l}\text { Age } \\
\text { (Years) }\end{array}$ & Pathology & DR & $\begin{array}{l}\text { BS } \\
(\mathrm{mL})\end{array}$ & $\begin{array}{l}\text { DR in } \\
\text { Stage } \\
\text { I-II }\end{array}$ & $\begin{array}{l}\text { DR in } \\
\text { Stage } \\
\text { III-IV }\end{array}$ & $\begin{array}{l}\text { DR in } \\
T \text { 1-2 }\end{array}$ & $\begin{array}{l}\text { DR in } \\
T \text { 3-4 }\end{array}$ & OS/PFS & HR & $\begin{array}{c}95 \% \text { CIs } \\
\text { (Hi) }\end{array}$ & $\begin{array}{c}95 \% \text { CIs } \\
\text { (Low) }\end{array}$ & $p$-Value \\
\hline $\begin{array}{l}\text { Zhao et al. } \\
\text { [32], 2019, } \\
\text { China }\end{array}$ & ISET & $\begin{array}{l}\text { 8-um pore } \\
\text { size }\end{array}$ & 55 & 20 & - & ESCC & $52.7 \%$ & 5 & $33.3 \%$ & $66.7 \%$ & $55.6 \%$ & $52.2 \%$ & OS & 1.84 & 0.60 & 5.66 & 0.290 \\
\hline $\begin{array}{l}\text { Han et al. } \\
\text { [86], 2019, } \\
\text { China }\end{array}$ & ISET & $\begin{array}{l}\text { 8-um pore } \\
\text { size }\end{array}$ & 60 & 0 & 62.2 & ESCC & $33.3 \%$ & 5 & $23.5 \%$ & $37.2 \%$ & $0.0 \%$ & $40.0 \%$ & PFS & 5.63 & 1.77 & 17.89 & 0.003 \\
\hline \multirow[t]{2}{*}{$\begin{array}{l}\text { Qiao et al. } \\
\text { [27], 2017, } \\
\text { China }\end{array}$} & $\begin{array}{l}\mathrm{CD} 45 \\
\text { magnetic } \\
\text { beads }\end{array}$ & pan-CK & 59 & 25 & 61.5 & ESCC & $79.7 \%$ & 7.5 & $23.5 \%$ & $69.0 \%$ & $12.5 \%$ & $60.8 \%$ & OS & 12.48 & 8.24 & 34.34 & 0.037 \\
\hline & & & & & & & & & & & & & PFS & 6.52 & 1.24 & 34.34 & 0.027 \\
\hline \multirow[t]{2}{*}{$\begin{array}{l}\text { Li et al. [54], } \\
\text { 2016, China }\end{array}$} & MACS & pan-CK & 140 & 25 & 62.8 & ESCC & $44.3 \%$ & 5 & $31.0 \%$ & $43.5 \%$ & $36.4 \%$ & $51.4 \%$ & OS & 1.82 & 0.91 & 4.88 & 0.046 \\
\hline & & & & & & & & & & & & & PFS & 1.86 & 0.87 & 3.15 & 0.035 \\
\hline $\begin{array}{l}\text { Woestemeier } \\
\text { et al. [82], } \\
2020, \\
\text { Germany }\end{array}$ & MACS & $\begin{array}{l}\text { pan-CK, } \\
\text { EpCAM }\end{array}$ & 90 & 0 & 63.7 & EC & $25.6 \%$ & 7.5 & $7.1 \%$ & $8.3 \%$ & $7.5 \%$ & $8.0 \%$ & OS & 0.72 & 0.30 & 1.76 & 0.474 \\
\hline \multirow[t]{2}{*}{$\begin{array}{c}\text { Konczalla } \\
\text { et al. [25], } \\
2019, \\
\text { Germany }\end{array}$} & CellSearch & $\begin{array}{l}\text { pan-CK, } \\
\text { EpCAM }\end{array}$ & 76 & 0 & - & EC & $19.7 \%$ & 7.5 & $17.9 \%$ & $21.6 \%$ & $10.3 \%$ & $25.5 \%$ & OS & 2.70 & 1.31 & 5.58 & 0.007 \\
\hline & & & & & & & & & & & & & PFS & 4.04 & 1.86 & 8.76 & 0.001 \\
\hline \multirow[t]{2}{*}{$\begin{array}{l}\text { Matsushita } \\
\text { et al. [13], } \\
\text { 2015, Japan }\end{array}$} & CellSearch & $\begin{array}{l}\text { pan-CK, } \\
\text { EpCAM }\end{array}$ & 90 & - & 65 & ESCC & $27.8 \%$ & 7.5 & $0.0 \%$ & $28.4 \%$ & $25.0 \%$ & $28.0 \%$ & OS & 2.56 & 1.15 & 5.68 & 0.021 \\
\hline & & & & & & & & & & & & & PFS & 1.25 & 0.65 & 2.31 & 0.497 \\
\hline \multirow[t]{2}{*}{$\begin{array}{l}\text { Reeh et al. } \\
\text { [26], 2015, } \\
\text { Germany }\end{array}$} & CellSearch & $\begin{array}{l}\text { pan-CK, } \\
\text { EpCAM }\end{array}$ & 100 & - & 66 & $\mathrm{EC}$ & $18.0 \%$ & 7.5 & $15.1 \%$ & $21.3 \%$ & $32.6 \%$ & $27.8 \%$ & OS & 3.13 & 1.49 & 6.56 & 0.003 \\
\hline & & & & & & & & & & & & & PFS & 5.06 & 2.23 & 11.48 & 0.001 \\
\hline $\begin{array}{l}\text { Tanaka et al. } \\
\text { [83], 2015, } \\
\text { Japan }\end{array}$ & CellSearch & $\begin{array}{l}\text { pan-CK, } \\
\text { EpCAM }\end{array}$ & 38 & - & 63 & $\mathrm{EC}$ & $50.0 \%$ & 7.5 & $20.0 \%$ & $50.0 \%$ & $40.0 \%$ & $44.4 \%$ & OS & 4.44 & 1.40 & 14.04 & 0.011 \\
\hline
\end{tabular}


Table 1. Cont.

\begin{tabular}{|c|c|c|c|c|c|c|c|c|c|c|c|c|c|c|c|c|c|}
\hline $\begin{array}{l}\text { Author Year, } \\
\text { Country }\end{array}$ & Technology & Molecules & SS & CS & $\begin{array}{l}\text { Age } \\
\text { (Years) }\end{array}$ & Pathology & DR & $\begin{array}{c}\text { BS } \\
(\mathrm{mL})\end{array}$ & $\begin{array}{c}\text { DR in } \\
\text { Stage } \\
\text { I-II }\end{array}$ & $\begin{array}{l}\text { DR in } \\
\text { Stage } \\
\text { III-IV }\end{array}$ & $\begin{array}{l}\text { DR in } \\
\text { T 1-2 }\end{array}$ & $\begin{array}{l}\text { DR in } \\
\text { T 3-4 }\end{array}$ & OS/PFS & HR & $\begin{array}{l}95 \% \text { CIs } \\
\text { (Hi) }\end{array}$ & $\begin{array}{l}\text { 95\% CIs } \\
\text { (Low) }\end{array}$ & $p$-Value \\
\hline \multirow[t]{2}{*}{$\begin{array}{l}\text { Pernot et al. } \\
\text { [84], 2017, } \\
\text { France }\end{array}$} & CellSearch & $\begin{array}{l}\text { pan-CK, } \\
\text { EpCAM }\end{array}$ & 106 & 0 & - & EAC & $46.2 \%$ & 7.5 & - & - & - & - & OS & 1.85 & 1.17 & 2.92 & 0.010 \\
\hline & & & & & & & & & & & & & PFS & 1.59 & 1.04 & 2.43 & 0.030 \\
\hline $\begin{array}{c}\text { Zhang et al. } \\
\text { [29], 2019, } \\
\text { China }\end{array}$ & SE-iFISH & $\begin{array}{l}\text { pan-CK/ } \\
\text { CEP8 }\end{array}$ & 63 & 50 &.- & ESCC & $74.6 \%$ & 7.5 & $21.1 \%$ & $32.0 \%$ & $20.0 \%$ & $26.4 \%$ & PFS & 3.92 & 0.91 & 16.95 & 0.047 \\
\hline $\begin{array}{c}\text { Brungs et al. } \\
\text { [85], 2018, } \\
\text { Australia }\end{array}$ & IsoFlux & $\begin{array}{l}\text { pan-CK/ } \\
\text { uPAR }\end{array}$ & 43 & 0 & 64 & EAC & $46.5 \%$ & 7.5 & $27.8 \%$ & $60.0 \%$ & - & - & OS & 3.70 & 1.20 & 12.4 & 0.030 \\
\hline \multirow[t]{4}{*}{$\begin{array}{l}\text { Ko et al. [75], } \\
\text { 2020, Korea }\end{array}$} & $\begin{array}{l}\text { ClearCell, } \\
\text { CTChip }\end{array}$ & $\begin{array}{c}\text { pan-CK/ } \\
\text { EpCAM/ } \\
\text { MUC1 } \\
\text { baseline }\end{array}$ & 57 & 19 & 63 & ESCC & $70.9 \%$ & 5 & - & - & - & - & OS & 0.97 & 0.44 & 2.14 & 0.946 \\
\hline & & & & & & & & & & & & & PFS & 1.35 & 0.69 & 2.63 & 0.380 \\
\hline & & $\begin{array}{c}\text { pan-CK/ } \\
\text { EpCAM/ } \\
\text { MUC1 } \\
\text { pre-cycle3 }\end{array}$ & & & & & & & & & & & Os & 3.58 & 1.63 & 7.84 & 0.001 \\
\hline & & & & & & & & & & & & & PFS & 3.68 & 1.73 & 7.81 & 0.001 \\
\hline $\begin{array}{c}\text { Chen et al. } \\
\text { [87], 2018, } \\
\text { China }\end{array}$ & $\begin{array}{l}\text { CanPatrol } \\
\text { RNA-FISH }\end{array}$ & Vimentin/twis & t 71 & 40 & 62.7 & ESCC & $64.8 \%$ & 5 & & - & - & - & PFS & 0.46 & 0.12 & 1.68 & 0.237 \\
\hline
\end{tabular}

SS: sample size; CS: control size; DR: detection rate; BS: blood sample; HR: hazard ratio; CI: confidence interval; ISET: isolation by size of epithelial tumor cells; MACS: magnetic cell separation system; CK: cytokeratin; EpCAM: epithelial cell adhesion molecule; OS: overall survival; PFS: progression-free survival; EC: esophageal cancer; ESCC: esophageal squamous cell carcinoma. EAC: esophageal adenocarcinoma. 


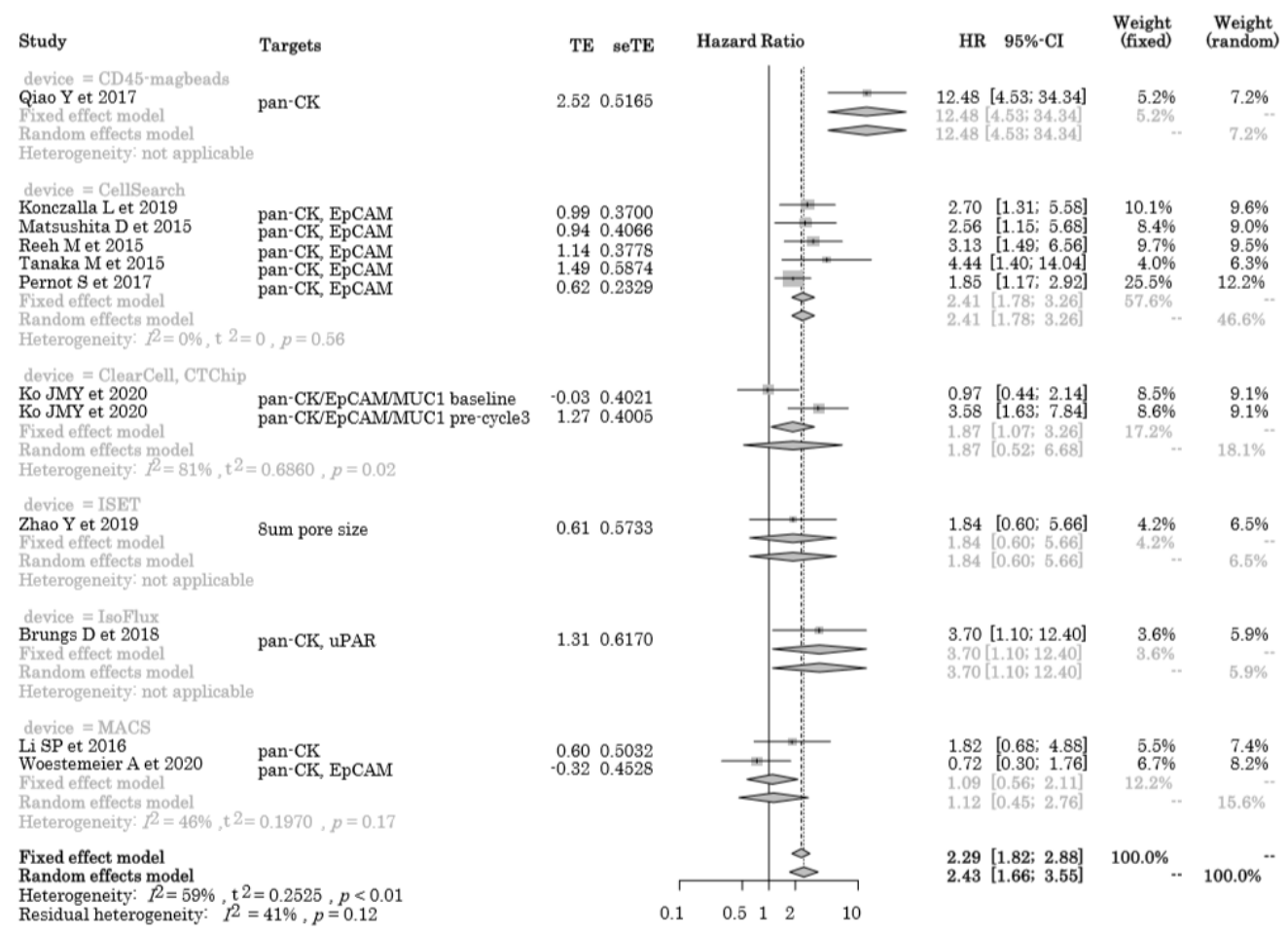

(a)

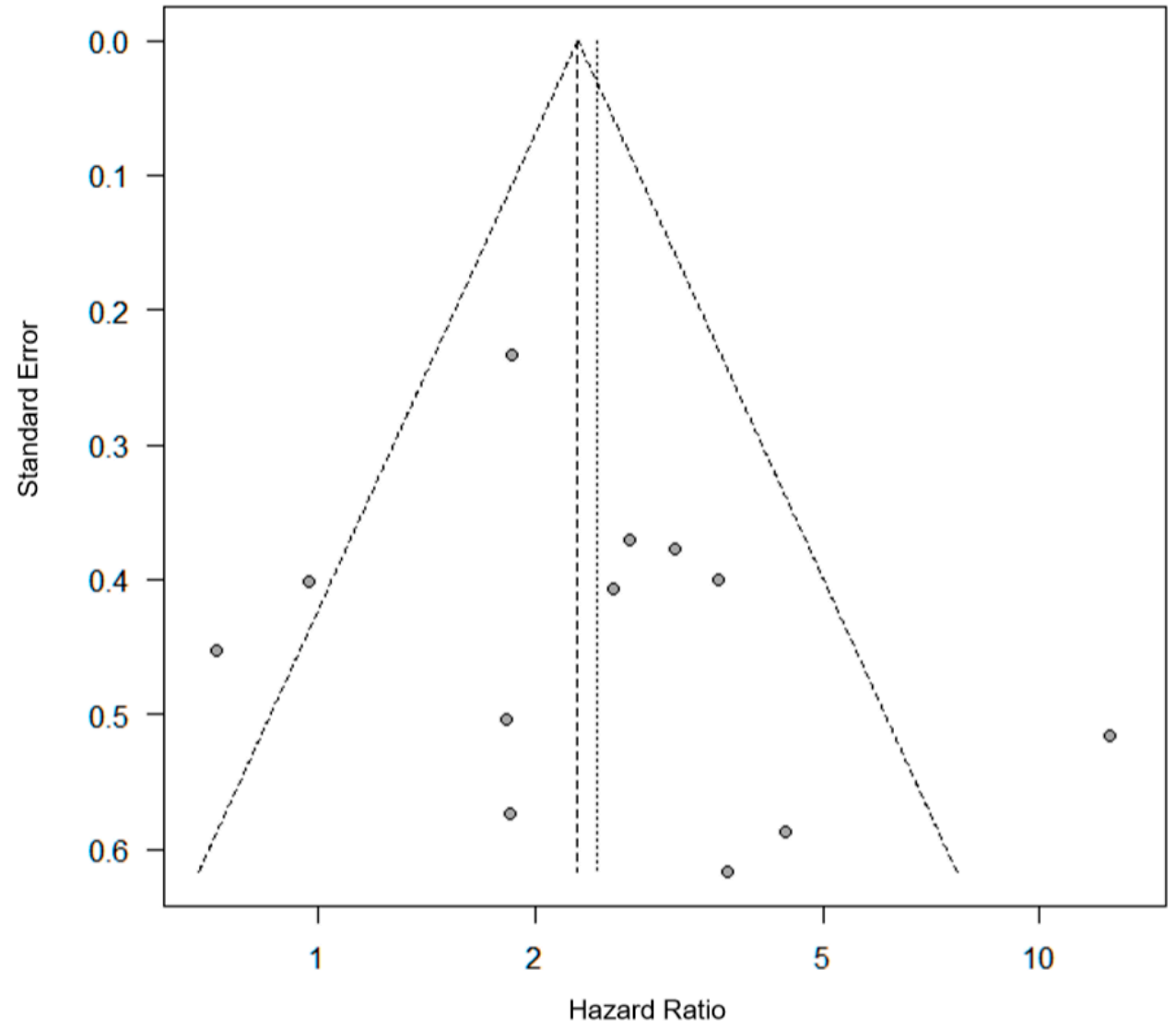

(b)

Figure 2. Cont. 


\begin{tabular}{|c|c|c|c|}
\hline Study & Targets & TE & seTE \\
\hline \multicolumn{4}{|l|}{ device $=$ ELISA } \\
\hline Nozoe T et 2005 & $\mathrm{CD} 4 / \mathrm{CD} 8$ ratio & 0.55 & 0.2688 \\
\hline Nozoe T et 2005 & CD8 & 0.73 & 0.2502 \\
\hline Jiao W et 2008 & Endothelin-1 & 0.97 & 0.2210 \\
\hline Blanchard P et 2012 & Kras & -0.22 & 0.3207 \\
\hline Blanchard P et 2012 & p53 & 0.69 & 0.1717 \\
\hline \multicolumn{4}{|l|}{$\begin{array}{l}\text { Fixed effect model } \\
\text { Random effects model }\end{array}$} \\
\hline $\begin{array}{l}\text { Random effects model } \\
\text { Heterogeneity: } \quad I^{2}=59 \%\end{array}$ & $\tau^{2}=0.0806 \quad p=0.04$ & & \\
\hline Heterogeneity: $\quad p^{2}=59 \%$ & & & \\
\hline \multicolumn{4}{|l|}{ device $=$ Fluorometer } \\
\hline Ko JMY et 2020 & cfDNA: baseline & 2.12 & 0.6307 \\
\hline $\begin{array}{l}\text { Ko JMY et } 2020 \\
\text { Fixed effect model }\end{array}$ & cfDNA: pre-cycle3 & 1.70 & 0.5833 \\
\hline \multicolumn{4}{|l|}{$\begin{array}{l}\text { Fixed effect model } \\
\text { Random effects model }\end{array}$} \\
\hline $\begin{array}{l}\text { Random effects model } \\
\text { Heterogeneity: } \quad 2=0 \%\end{array}$ & $\tau^{2}=0, p=0.62$ & & \\
\hline \multicolumn{4}{|l|}{ device $=\mathrm{qRT}-\mathrm{PCR}$} \\
\hline Hu HB et 2016 & Inc: CFLAR-AS1 & 0.52 & 0.1662 \\
\hline Hu HB et 2016 & Inc: Linc00152 & 0.64 & 0.1595 \\
\hline Hu HB et 2016 & Inc: POU3F3 & 0.60 & 0.1639 \\
\hline Li J et 2017 & miR-15a & 1.43 & 0.4774 \\
\hline & $\mathrm{miR}-21$ & 0.62 & 0.6197 \\
\hline Wu C et 2014 & miR-25 & 0.12 & 0.1905 \\
\hline Wu C et 2014 & $\mathrm{miR}-25$ & 1.35 & 0.6747 \\
\hline Wu C et 2014 & miR-100 & 1.43 & 0.6346 \\
\hline Tanaka K et 2013 & $\mathrm{miR}-200 \mathrm{c}$ & 1.03 & 0.5349 \\
\hline Wu C et 2014 & miR-223 & 0.54 & 0.2093 \\
\hline Lv H et 2016 & miR-375 & -0.43 & 0.1419 \\
\hline Wu C et 2014 & miR-375 & 0.56 & 0.2317 \\
\hline Zhai $R$ et 2015 & miR-3935, 4286 & 2.39 & 0.9193 \\
\hline Li SP et 2016 & miR-506 & 0.85 & 0.2954 \\
\hline Guan S et 2016 & miR-613 & -0.53 & 0.2430 \\
\hline Hoffmann AC et 2010 & Survivin & 1.89 & 0.6171 \\
\hline Cao M et 2009 & Survivin & 1.64 & 0.4145 \\
\hline He X et 2019 & UPA & 0.60 & 0.2293 \\
\hline \multirow{2}{*}{\multicolumn{4}{|c|}{$\begin{array}{l}\text { Fixed effect model } \\
\text { Random effects model }\end{array}$}} \\
\hline & & & \\
\hline Heterogeneity: $\quad R^{2}=81 \%$ & $\tau^{2}=0.2639, \quad, p<0.01$ & & \\
\hline \multicolumn{4}{|c|}{$\begin{array}{l}\text { Fixed effect model } \\
\text { Random effects model }\end{array}$} \\
\hline $\begin{array}{l}\text { Heterogeneity: } \quad 12=79 \% \\
\text { Residual heterogeneity: }\end{array}$ & $\begin{array}{l}\tau^{2}=0.2425, p<0.01 \\
2^{2}=78 \%, p<0.01\end{array}$ & & \\
\hline
\end{tabular}

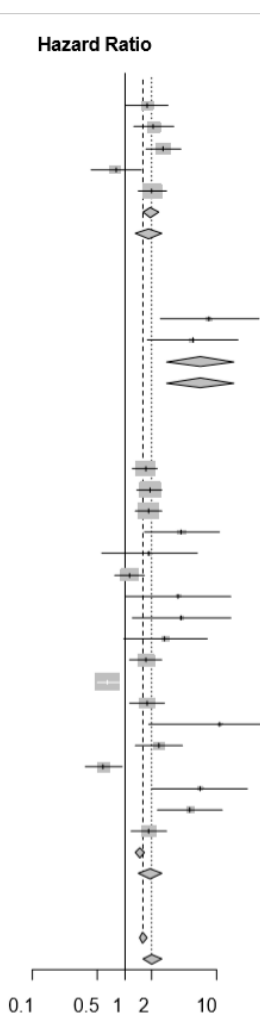

(73) $\begin{array}{ll}1.73 & {[1.02 ; 2.93]} \\ 2.07 & {[1.27 ; 3.38]}\end{array}$ $0.80 \quad 0.43,1.50]$ $200 \quad[1.43 ; 280]$ $1.90[1.55 ; 2.33]$ $1.81[1.30 ; 2.51]$ Weight (fixed) (random) $\begin{array}{ll}3.4 \% & 4.6 \% \\ 4.0 \% & 4.8 \% \\ 5.1 \% & 5.0 \% \\ 2.4 \% & 4.2 \% \\ 8.4 \% & 5.4 \%\end{array}$ $8.4 \%$ - $24.1 \%$ $\begin{array}{lll}8.34[2.42 ; 28.70] & 0.6 \% & 2.3 \% \\ 5.45[1.74 ; 17.10] & 0.7 \% & 2.5 \%\end{array}$ $\begin{array}{lll}6.63[2.86 ; 15.35] & 1.4 \% & \\ 6.63[2.86 ; 15.35] & - & 4.8 \%\end{array}$

$1.68 \quad[1.21 ; 2.32$ $1.82[1.32 ; 2.51]$ 4.17 [1.64; 10.63] $85[1.64 ; 10.63]$ $13[0.78,164]$ $3.84[1.02 ; 14.41]$ $4.18[1.20 ; 14.50]$ $2.79[0.98 ; 7.96]$ $1.72 \quad[1.14 ; 2.59]$ $0.65 \quad[0.49 ; 0.86]$ $1.75[1.11 ; 2.76]$ $235[1.80 ; 66.12]$ $\begin{array}{lll}2.35 & {[1.32 ; 4.20} \\ 0.59 & {[0.37 ; 0.95]}\end{array}$ $6.60[1.97 ; 22.12]$ $5.17[2.29 ; 11.65]$ $1.48[1.32 ; 1.65]$
$1.92[1.43 ; 2.56]$

$\begin{array}{ll}9.0 \% & 5.4 \% \\ 9.8 \% & 5.5 \% \\ 9.2 \% & 5.4 \%\end{array}$

$\begin{array}{ll}9.2 \% & 5.4 \% \\ 1.1 \% & 3.1 \% \\ 0.6 \% & 2.3 \%\end{array}$ $6.8 \% \quad 5 \%$ \begin{tabular}{ll}
$0.5 \%$ & $5.2 \%$ \\
\hline & $2.1 \%$
\end{tabular} $\begin{array}{ll}0.6 \% & 2.3 \% \\ 0.9 \% & 2.8 \%\end{array}$ $5.7 \% \quad 5.1 \%$ \begin{tabular}{ll}
$2.3 \%$ & $5.6 \%$ \\
$4.6 \%$ & $4.9 \%$ \\
\hline
\end{tabular} $0.3 \% \quad 1.3 \%$ $2.8 \% \quad 4.4 \%$ $\begin{array}{ll}4.2 \% & 4.8 \% \\ 0.7 \% & 2.3 \% \\ 1.4 \% & 3.5 \%\end{array}$ $\begin{array}{ll}1.4 \% & 3.5 \% \\ 4.7 \% & 5.0 \%\end{array}$ $\begin{array}{rr}4.7 \% & 5.0 \% \\ 75.3 \% & -71.2 \%\end{array}$ $1.60[1.45 ; 1.76] \quad 100.0 \%$ $1.98[1.56 ; 2.51]-100.0 \%$

(c)

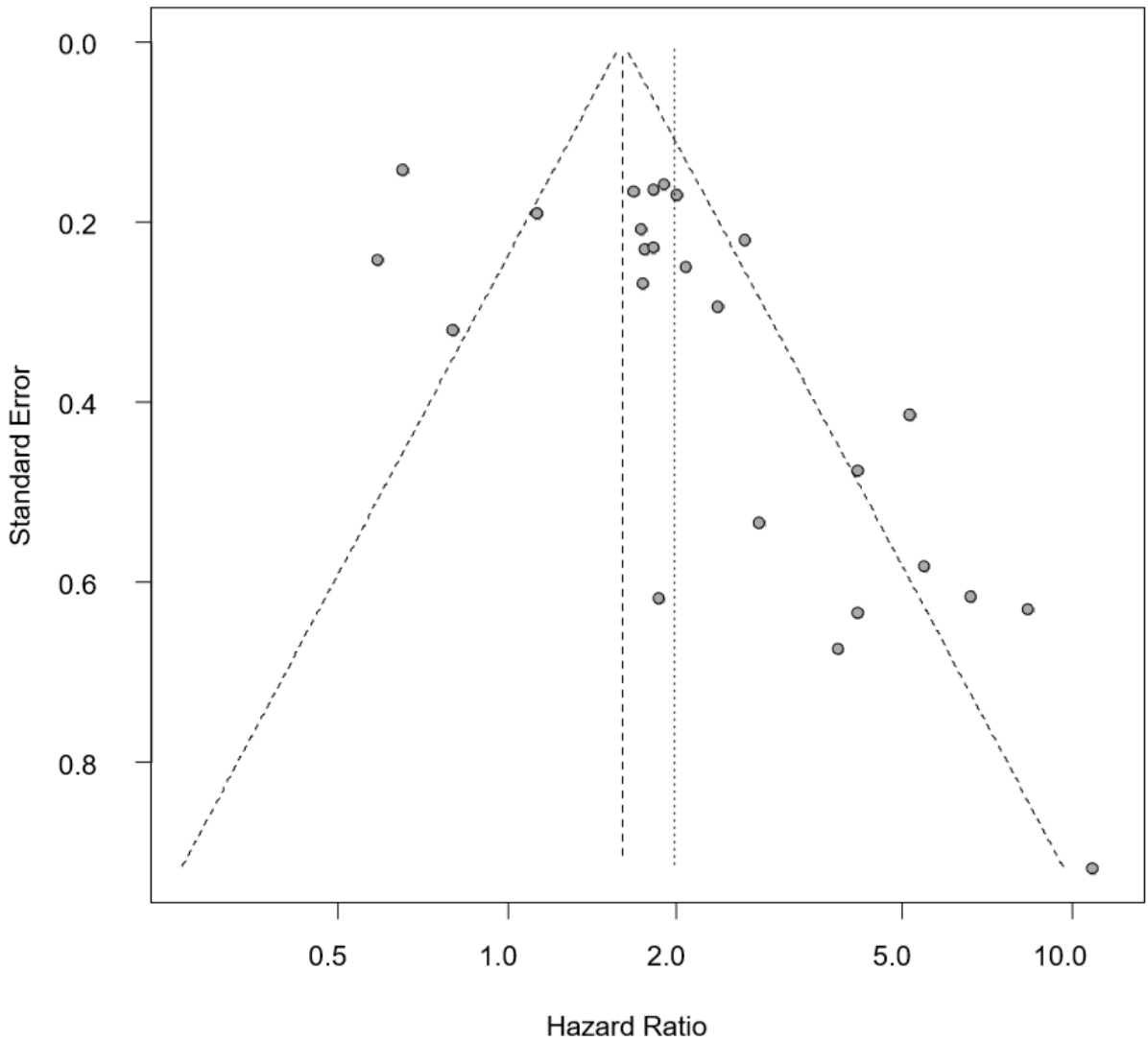

(d)

Figure 2. The overall survival (OS) analysis of liquid biopsies. (a) Forest plot of the hazard ratio for OS in the cytometric assay; (b) funnel plot for the publication bias of (a); (c) forest plot of the hazard ratio for OS in the non-cytometric assay; (d) funnel plot for the publication bias of (c). 


\subsubsection{OS in the Non-Cytometric Assay}

A total of fifteen studies were enrolled for the OS analysis of 1721 EC patients $[39,44,47,48,50$, $52-55,73,75,88-91]$. In this cohort, the average age was 61.5 years (54.3-68.7) and the median CTC positivity rate was $32.2 \%$ (22.6-77.0). The median CTC detection rates in stages I-II and III-IV were $43.2 \%$ (20.9-70.3) and 60.2\% (28.4-64.6), respectively. The median CTC detection rates in T 1-2 and 3-4 were $34.5 \%(7.7-45.5)$ and $39.4 \%(25.4-62.0)$, respectively (Table 2).

The pooled HR for OS was $1.98(95 \% \mathrm{CI}=1.56-2.51)$, and poorer OS was observed in CTC-positive patients compared with CTC-negative patients (Figure 2c). A combination of miRNA-3935 and miRNA-4286 [53] appeared to exhibit the most powerful prognostic predictive value. There were no significant differences between each detection method because of the heterogeneity of this cohort $\left(I^{2}=79 \%, p<0.01\right)$ and the existence of publication bias was visualized as a funnel plot (Figure $2 \mathrm{~d}$ ).

\subsection{Progression-Free Survival (PFS) in the Cytometric Assay}

A total of ten studies were enrolled for the PFS analysis of 822 EC patients $[13,25-27,29,54,75,84$, $86,87]$. In this cohort, the average age was 63.3 years (61.5-66) and the median CTC positivity rate was $46.2 \%$ (18.0-79.7). The median CTC detection rates in stages I-II and III-IV were $21.1 \%(0.0-31.0)$ and $32.0 \%$ (21.3-69.0), respectively. The median CTC detection rates in T 1-2 and 3-4 were $20.0 \%(0.0-36.4)$ and $28.0 \%(25.5-60.8)$, respectively (Table 1$)$.

The pooled HR for PFS was $2.31(95 \% \mathrm{CI}=1.57-3.40)$, and poorer OS was observed in CTC-positive patients compared to CTC-negative patients (Figure 3a). The negative selection with CD45 magnetic beads [27] and positive selection with ISET [86] appeared to give the most powerful prognostic predictive value. There were no significant differences between each detection method because of the heterogeneity of this cohort $\left(I^{2}=62 \%, p<0.01\right)$, and publication bias was visualized as a funnel plot (Figure 3b).

\subsection{PFS in the Non-Cytometric Assay}

A total of ten studies were enrolled for the PFS analysis of 1712 EC patients $[8,39,40,42,47,49,51,52$, $54,55,75,89,90,92-94]$. In this cohort, the average age was 62.3 years (58.9-66), and the median CTC positive rate was $35.5 \%$ (16.8-54.2). The median CTC detection rates in stages I-II and III-IV were $20.3 \%$ (15.3-38.1) and 55.9\% (18.6-64.6), respectively. The median CTC detection rates in T 1-2 and 3-4 were $21.1 \%$ (7.7-40.3) and $48.1 \%$ (16.7-65.4), respectively (Table 2).

The pooled HR for PFS was $1.60(95 \% \mathrm{CI}=1.19-2.16)$, and no significant difference was observed between CTC-positive and CTC-negative patients (Figure 3c). Overall, miRNA-21 [49] and SCC mRNA [8] appeared to exhibit the most powerful prognostic predictive value. There were no significant differences between each detection method because of the heterogeneity of this cohort $\left(I^{2}=85 \%, p<0.01\right)$, and the existence of publication bias was visualized as a funnel plot (Figure $3 \mathrm{~d}$ ). 
Table 2. The results of liquid biopsies for prognostic evaluation in the non-cytometric assays.

\begin{tabular}{|c|c|c|c|c|c|c|c|c|c|c|c|c|c|c|c|c|c|}
\hline $\begin{array}{l}\text { Author, Year, } \\
\text { Country }\end{array}$ & Technology & Molecules & SS & CS & $\begin{array}{l}\text { Age } \\
\text { (Years) }\end{array}$ & Pathology & DR & $\begin{array}{l}\text { BS } \\
(\mathrm{mL})\end{array}$ & $\begin{array}{l}\text { DR in } \\
\text { Stage } \\
\text { I-II }\end{array}$ & $\begin{array}{l}\text { DR in } \\
\text { Stage } \\
\text { III-IV }\end{array}$ & $\begin{array}{l}\text { DR in } \\
T \text { 1-2 }\end{array}$ & $\begin{array}{l}\text { DR in } \\
\text { T 3-4 }\end{array}$ & OS/PFS & HR & $\begin{array}{l}\text { 95\% CIs } \\
\text { (Hi) }\end{array}$ & $\begin{array}{l}\text { 95\% CIs } \\
\text { (Low) }\end{array}$ & $p$-Value \\
\hline \multirow[t]{4}{*}{$\begin{array}{l}\text { Ko et al. [75], } \\
\text { 2020, Korea }\end{array}$} & \multirow[t]{2}{*}{ Fluorometer } & \multirow[t]{2}{*}{$\begin{array}{l}\text { cfDNA: } \\
\text { Baseline }\end{array}$} & \multirow[t]{2}{*}{57} & \multirow[t]{2}{*}{19} & \multirow[t]{2}{*}{63.0} & \multirow[t]{2}{*}{ ESCC } & \multirow[t]{2}{*}{-} & \multirow[t]{2}{*}{5} & \multirow[t]{2}{*}{-} & \multirow[t]{2}{*}{-} & \multirow[t]{2}{*}{ - } & \multirow[t]{2}{*}{-} & OS & 8.34 & 2.42 & 28.7 & 0.001 \\
\hline & & & & & & & & & & & & & PFS & 1.96 & 0.67 & 5.76 & 0.222 \\
\hline & \multirow[t]{2}{*}{ Fluorometer } & \multirow{2}{*}{$\begin{array}{l}\text { cfDNA: } \\
\text { Pre-cycle3 }\end{array}$} & \multirow[t]{2}{*}{57} & \multirow[t]{2}{*}{19} & \multirow{2}{*}{63.0} & \multirow{2}{*}{ ESCC } & \multirow[t]{2}{*}{-} & \multirow[t]{2}{*}{5} & \multirow[t]{2}{*}{-} & \multirow[t]{2}{*}{-} & \multirow[t]{2}{*}{-} & \multirow[t]{2}{*}{-} & OS & 5.45 & 1.74 & 17.1 & 0.004 \\
\hline & & & & & & & & & & & & & PFS & 1.68 & 0.7 & 4.06 & 0.249 \\
\hline \multirow[t]{2}{*}{$\begin{array}{l}\text { Nozoe et al. } \\
\text { [39], 2005, } \\
\text { Japan }\end{array}$} & \multirow[t]{2}{*}{ ELISA } & \multirow[t]{2}{*}{$\begin{array}{l}\mathrm{CD} 4 / \mathrm{CD} 8 \\
\text { ratio }\end{array}$} & \multirow[t]{2}{*}{134} & \multirow[t]{2}{*}{-} & \multirow[t]{2}{*}{62.0} & ESCC & $35.80 \%$ & - & $38.10 \%$ & $32.00 \%$ & $40.30 \%$ & $31.90 \%$ & OS & 1.73 & 1.02 & 2.93 & 0.043 \\
\hline & & & & & & & & & & & & & PFS & 2.07 & 1.26 & 3.38 & 0.004 \\
\hline $\begin{array}{l}\text { Jiao et al. [88], } \\
\text { 2008, China }\end{array}$ & ELISA & Endothelin-1 & 108 & 82 & 64.5 & ESCC & - & - . & - & - & - & - & OS & 2.63 & 1.38 & 4.05 & 0.003 \\
\hline $\begin{array}{c}\text { Blanchard } \\
\text { et al. [89], } \\
\text { 2012, France }\end{array}$ & ELISA & Kras & 84 & - & 60.0 & $\mathrm{EC}$ & $22.60 \%$ & - & - & - & $7.70 \%$ & $25.40 \%$ & OS & 0.8 & 0.5 & 1.5 & 0.5 \\
\hline & ELISA & p53 & 84 & - & 60.0 & $\mathrm{EC}$ & $28.60 \%$ & - & - & - & $7.70 \%$ & $32.40 \%$ & $\begin{array}{l}\text { PFS } \\
\text { OS } \\
\text { PFS }\end{array}$ & $\begin{array}{c}0.8 \\
2 \\
2\end{array}$ & $\begin{array}{c}0.5 \\
1.05 \\
1\end{array}$ & $\begin{array}{l}1.4 \\
2.8 \\
3.9\end{array}$ & $\begin{array}{c}0.5 \\
0.04 \\
0.04\end{array}$ \\
\hline $\begin{array}{l}\text { Kimura et al. } \\
\text { [40], 2008, } \\
\text { Japan }\end{array}$ & ELISA & VEGF-C & 80 & 20 & 62.8 & EC & - & - & - & - & - & - & PFS & 5.6 & 1.6 & 19.6 & 0.007 \\
\hline $\begin{array}{l}\text { Hu et al. [73], } \\
\text { 2016, China }\end{array}$ & qRT-PCR & $\begin{array}{c}\ln c \\
\text { CFLAR-AS1 }\end{array}$ & 205 & 210 & 54.3 & ESCC & - & - & - & - & - & - & OS & 1.68 & 1.08 & 2.32 & N.D. \\
\hline & & Linc00152 & 205 & 210 & 54.3 & ESCC & - & - & - & - & - & - & OS & 1.89 & 1.22 & 2.58 & N.D. \\
\hline & & lnc POU3F3 & 205 & 210 & 54.3 & ESCC & - & - & - & - & - & - & OS & 1.82 & 1.17 & 2.51 & N.D. \\
\hline $\begin{array}{l}\text { Li et al. [47], } \\
\text { 2017, China }\end{array}$ & qRT-PCR & miR-15a & 106 & 106 & 62.3 & $\mathrm{EC}$ & - & - & - & - & - & - & OS & 4.17 & 1.97 & 10.63 & 0.01 \\
\hline & & & & & & & & & & & & & PFS & 4.01 & 1.62 & 9.82 & 0.01 \\
\hline $\begin{array}{l}\text { Lv et al. [48], } \\
\text { 2016, China }\end{array}$ & qRT-PCR & miR-21 & 126 & 80 & 59.1 & ESCC & - & - & $48.40 \%$ & $60.90 \%$ & $34.50 \%$ & $62.00 \%$ & OS & 1.85 & 1.48 & 6.24 & 0.012 \\
\hline & & miR-375 & 126 & 80 & 59.1 & ESCC & - & - & $66.10 \%$ & $34.40 \%$ & $45.50 \%$ & $39.40 \%$ & OS & 0.65 & 0.27 & 0.86 & 0.041 \\
\hline $\begin{array}{l}\text { Komatsu et al. } \\
\text { [49], 2016, } \\
\text { Japan }\end{array}$ & qRT-PCR & miR-21 & 37 & 20 & - & ESCC & $43.20 \%$ & 7 & - & - & - & - & PFS & 9.95 & 1.56 & 63.42 & 0.015 \\
\hline
\end{tabular}


Table 2. Cont.

\begin{tabular}{|c|c|c|c|c|c|c|c|c|c|c|c|c|c|c|c|c|c|}
\hline $\begin{array}{l}\text { Author, Year, } \\
\text { Country }\end{array}$ & Technology & Molecules & SS & CS & $\begin{array}{l}\text { Age } \\
\text { (Years) }\end{array}$ & Pathology & DR & $\begin{array}{l}\text { BS } \\
(\mathrm{mL})\end{array}$ & $\begin{array}{l}\text { DR in } \\
\text { Stage } \\
\text { I-II }\end{array}$ & $\begin{array}{l}\text { DR in } \\
\text { Stage } \\
\text { III-IV }\end{array}$ & $\begin{array}{l}\text { DR in } \\
T \text { 1-2 }\end{array}$ & $\begin{array}{l}\text { DR in } \\
\text { T 3-4 }\end{array}$ & OS/PFS & HR & $\begin{array}{l}\text { 95\% CIs } \\
\text { (Hi) }\end{array}$ & $\begin{array}{l}95 \% \text { CIs } \\
\text { (Low) }\end{array}$ & $p$-Value \\
\hline \multirow[t]{5}{*}{$\begin{array}{l}\text { Wu et al. [50], } \\
\text { 2014, China }\end{array}$} & qRT-PCR & miR-25 & 194 & 94 & - & ESCC & - & 2 & $61.90 \%$ & $62.50 \%$ & - & - & OS & 1.13 & 0.78 & 1.64 & 0.526 \\
\hline & & miR-25 & 63 & 63 & - & ESCC & - & 3 & - & - & - & - & OS & 3.84 & 1.02 & 14.41 & 0.046 \\
\hline & & miR-100 & 63 & 63 & - & ESCC & - & 3 & - & - & - & - & OS & 4.18 & 1.21 & 14.5 & 0.024 \\
\hline & & miR-223 & 194 & 94 & - & ESCC & - & 2 & $56.80 \%$ & $59.40 \%$ & - & - & OS & 1.72 & 1.14 & 2.59 & 0.01 \\
\hline & & miR-375 & 194 & 94 & - & ESCC & - & 2 & $70.30 \%$ & $64.10 \%$ & - & - & OS & 1.75 & 1.11 & 2.76 & 0.016 \\
\hline \multirow[t]{4}{*}{$\begin{array}{l}\text { Gu et al. [51], } \\
\text { 2018, China }\end{array}$} & qRT-PCR & miR-25-3p & 329 & - & 61.7 & EAC & - & - & - & - & - & - & PFS & 1.04 & 0.73 & 1.25 & 0.817 \\
\hline & & miR-30c-5p & 329 & - & 61.7 & EAC & -. & - & - & - & - & - & PFS & 0.86 & 0.61 & 1.22 & 0.397 \\
\hline & & miR-152-3p & 329 & - & 61.7 & EAC & - & - & - & - & - & - & PFS & 0.78 & 0.54 & 1.11 & 0.161 \\
\hline & & miR-331-3p & 329 & - & 61.7 & EAC & - & - & - & - & - & - & PFS & 0.55 & 0.38 & 0.78 & 0.001 \\
\hline \multirow[t]{2}{*}{$\begin{array}{l}\text { Tanaka et al. } \\
\text { [52], 2013, } \\
\text { Japan }\end{array}$} & qRT-PCR & miR-200c & 64 & 27 & - & ESCC & - & 8 & $28.00 \%$ & $64.10 \%$ & $30.00 \%$ & $59.10 \%$ & OS & 2.79 & 1.11 & 7.96 & N.D. \\
\hline & & & & & & & & & & & & & PFS & 2.79 & 1.11 & 7.96 & 0.029 \\
\hline $\begin{array}{l}\text { Zhai et al. } \\
\text { [53], 2015, } \\
\text { China }\end{array}$ & qRT-PCR & $\begin{array}{l}\text { miR-3935, } \\
\quad 4286\end{array}$ & 30 & 30 & 68.7 & $\mathrm{EC}$ & - & - & - & - & - & - & OS & 10.91 & 1.8 & 66.12 & 0.009 \\
\hline \multirow[t]{2}{*}{$\begin{array}{l}\text { Li et al. [54], } \\
\text { 2016, China }\end{array}$} & qRT-PCR & miR-506 & 100 & 40 & 59.2 & ESCC & - & 5 & $30.40 \%$ & $51.90 \%$ & $35.40 \%$ & $48.10 \%$ & OS & 2.35 & 1.32 & 4.2 & 0.004 \\
\hline & & & & & & & & & & & & & PFS & 2.65 & 1.53 & 4.58 & 1 \\
\hline \multirow[t]{2}{*}{$\begin{array}{l}\text { Guan et al. } \\
\text { [55], 2016, } \\
\text { China }\end{array}$} & qRT-PCR & miR-613 & 75 & 75 & 65.0 & ESCC & - & - & - & - & - & - & OS & 0.59 & 0.34 & 0.95 & 0.031 \\
\hline & & & & & & & & & & & & & PFS & 0.66 & 0.48 & 0.89 & 0.006 \\
\hline $\begin{array}{l}\text { Setoyama et } \\
\text { al. [42], 2006, } \\
\text { Japan }\end{array}$ & qRT-PCR & CEA & 106 & 28 & 63.3 & $\mathrm{EC}$ & $36.80 \%$ & 5 & $19.70 \%$ & $60.00 \%$ & $18.30 \%$ & $56.50 \%$ & PFS & 0.53 & 0.32 & 0.8 & 0.002 \\
\hline $\begin{array}{l}\text { Tanaka et al. } \\
\text { [92], 2010, } \\
\text { Japan }\end{array}$ & qRT-PCR & CEA, SCC & 244 & - & - & ESCC & $16.80 \%$ & 8 & $15.30 \%$ & $18.60 \%$ & $17.00 \%$ & $16.70 \%$ & PFS & 1.65 & 1.03 & 2.63 & 0.037 \\
\hline $\begin{array}{l}\text { Yin et al. [93], } \\
\text { 2012, China }\end{array}$ & qRT-PCR & $\begin{array}{c}\text { CEA, } \\
\text { survivin, } \\
\text { CK19 }\end{array}$ & 72 & - & 63.0 & $\mathrm{EC}$ & $54.20 \%$ & - & - & - & - & - & PFS & 3.68 & 1.38 & 9.84 & 0.008 \\
\hline
\end{tabular}


Table 2. Cont.

\begin{tabular}{|c|c|c|c|c|c|c|c|c|c|c|c|c|c|c|c|c|c|}
\hline $\begin{array}{l}\text { Author, Year, } \\
\text { Country }\end{array}$ & Technology & Molecules & SS & CS & $\begin{array}{l}\text { Age } \\
\text { (Years) }\end{array}$ & Pathology & DR & $\begin{array}{c}\text { BS } \\
(\mathrm{mL})\end{array}$ & $\begin{array}{l}\text { DR in } \\
\text { Stage } \\
\text { I-II }\end{array}$ & $\begin{array}{l}\text { DR in } \\
\text { Stage } \\
\text { III-IV }\end{array}$ & $\begin{array}{l}\text { DR in } \\
T \text { 1-2 }\end{array}$ & $\begin{array}{l}\text { DR in } \\
\text { T 3-4 }\end{array}$ & OS/PFS & HR & $\begin{array}{l}95 \% \text { CIs } \\
\text { (Hi) }\end{array}$ & $\begin{array}{l}95 \% \text { CIs } \\
\text { (Low) }\end{array}$ & $p$-Value \\
\hline $\begin{array}{l}\text { Honma et al. } \\
\text { [94], 2006, } \\
\text { Japan }\end{array}$ & qRT-PCR & SCC & 46 & 42 & 66.0 & ESCC & $30.40 \%$ & 3 & $16.70 \%$ & $39.30 \%$ & $21.10 \%$ & $37.00 \%$ & PFS & 3 & 1.05 & 8.54 & 0.04 \\
\hline $\begin{array}{l}\text { Kaganoi et al. } \\
\text { [8], 2004, } \\
\text { Japan }\end{array}$ & qRT-PCR & SCC & 70 & 19 & - & ESCC & $32.80 \%$ & 10 & $18.80 \%$ & $63.60 \%$ & $13.60 \%$ & $65.40 \%$ & PFS & 7.15 & 1.25 & 61.1 & 0.038 \\
\hline $\begin{array}{c}\text { Hoffmann } \\
\text { et al. [44], } \\
2010, \\
\text { Germany }\end{array}$ & qRT-PCR & Survivin & 62 & - & - & $\mathrm{EC}$ & $77.00 \%$ & - & - & - & - & - & OS & 6.6 & 1.97 & 22.12 & 0.002 \\
\hline \multirow[t]{2}{*}{$\begin{array}{l}\text { Cao et al. [90], } \\
\text { 2009, China }\end{array}$} & qRT-PCR & Survivin & 108 & 75 & 58.9 & ESCC & $47.20 \%$ & 2 & $20.90 \%$ & $64.60 \%$ & $36.50 \%$ & $57.10 \%$ & OS & 5.17 & 2.3 & 11.65 & 0.001 \\
\hline & & & & & & & & & & & & & PFS & 5.18 & 2.42 & 8.93 & 0.005 \\
\hline \multirow[t]{2}{*}{$\begin{array}{l}\text { He et al. [91], } \\
\text { 2019, China }\end{array}$} & qRT-PCR & uPA & 205 & - & - & ESCC & $25.90 \%$ & - & $22.90 \%$ & $28.40 \%$ & $16.70 \%$ & $29.70 \%$ & OS & 1.82 & 1.16 & 2.85 & 0.009 \\
\hline & & & & & & & & & & & & & PFS & 1.97 & 1.11 & 3.49 & 0.02 \\
\hline
\end{tabular}

SS: sample size; CS: control size; DR: detection rate; BS: blood sample; HR: hazard ratio; CI: confidence interval; CEA: carcinoembryonic antigen; SCC: squamous cell carcinoma antigen. 

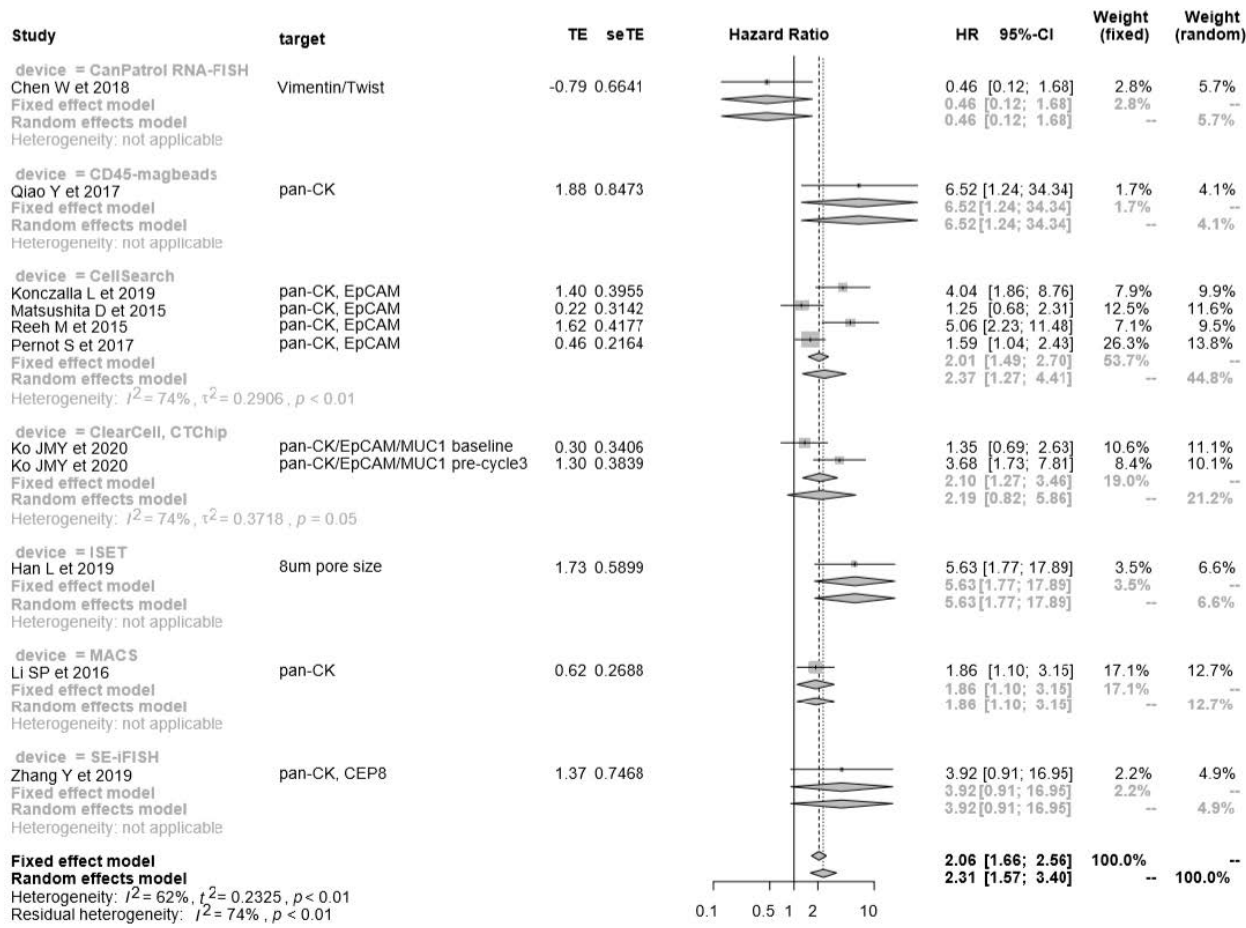

(a)

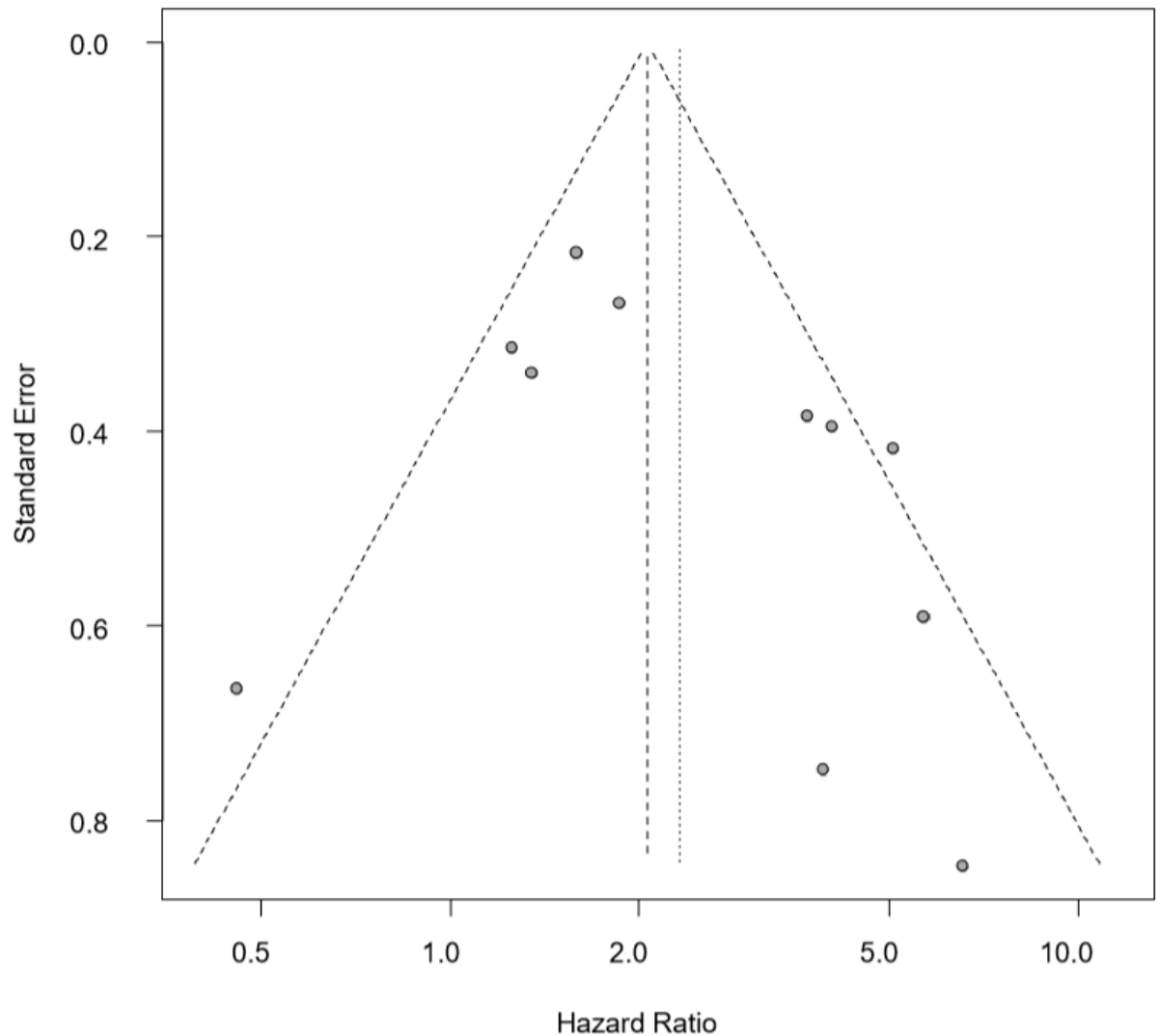

(b)

Figure 3. Cont. 


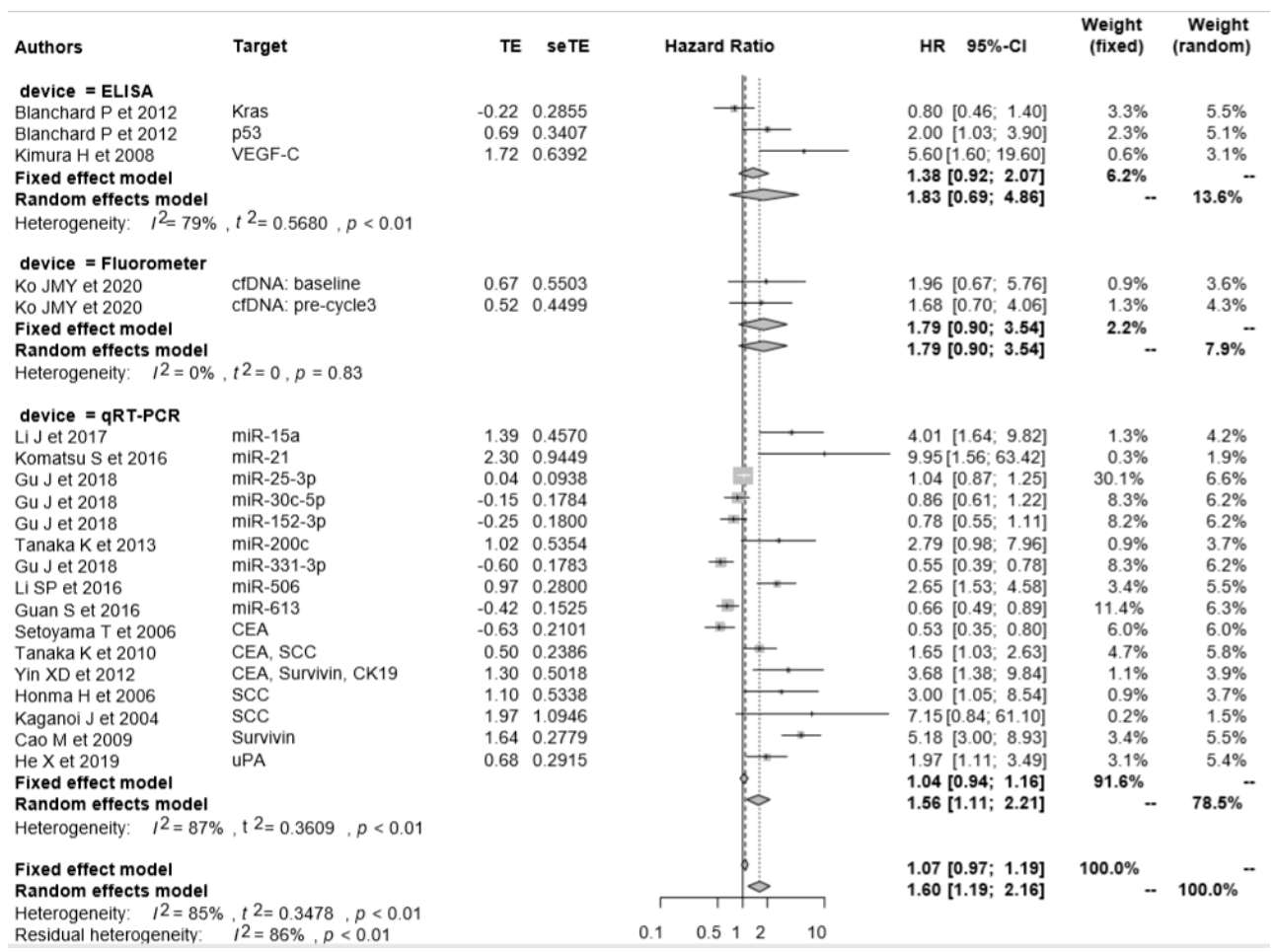

(c)

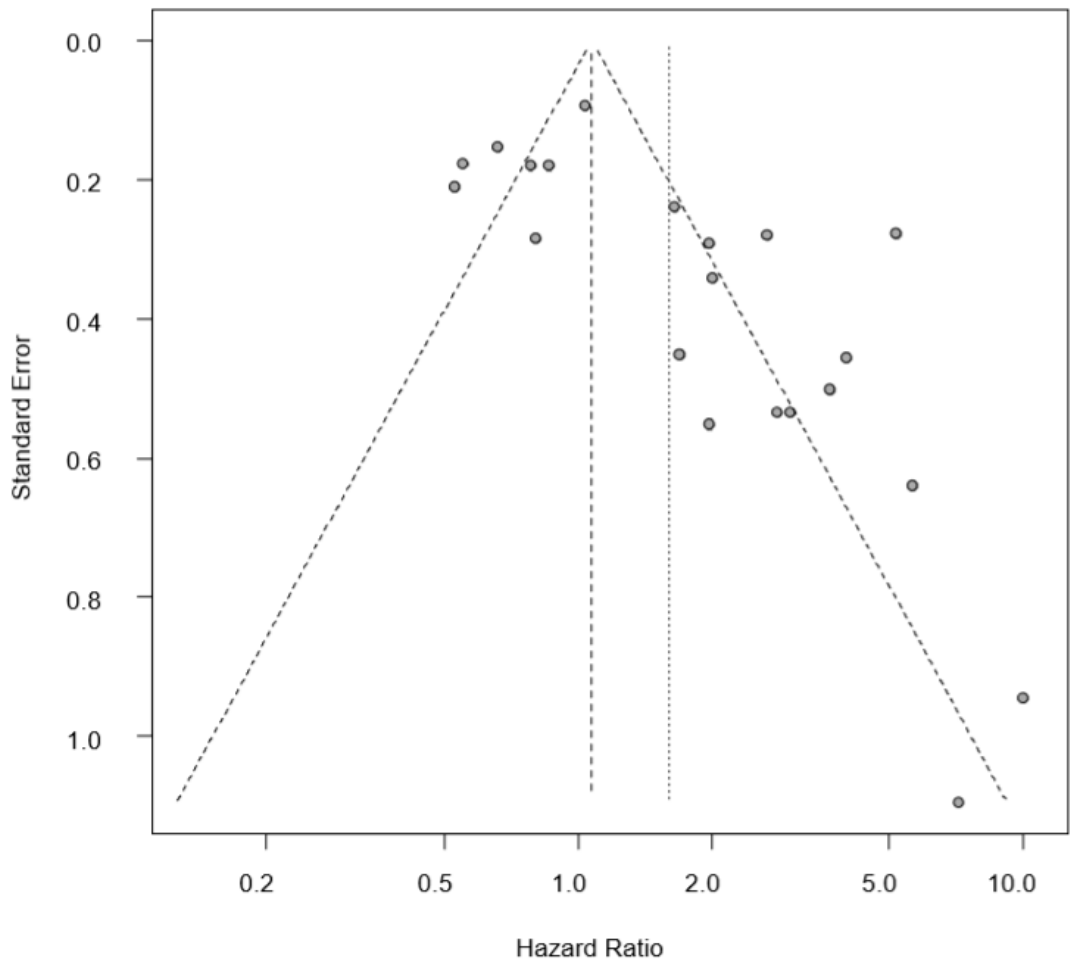

(d)

Figure 3. The progression free survival (FS) analysis of liquid biopsies. (a) Forest plot of the hazard ratio for PFS in the cytometric assay; (b) funnel plot for the publication bias of (a); (c) forest plot of the hazard ratio for PFS in the non-cytometric assays; (d) funnel plot for the publication bias of (c).

\subsection{Early Diagnostic Value of "Liquid Biopsy"}

Twenty-six molecules from twenty studies demonstrated the diagnostic value of using a liquid biopsy by using the area under the curve (AUC) for the early detection of ECs $[49,50,54,56-58,60-67$, 
72,75,78-80,95-97] (Table 3). It is still challenging to detect early EC or make a differential diagnosis between high-grade dysplasia and EC using a liquid biopsy strategy. In Figure 4a, the AUC values have been plotted, featuring 95\% CIs. The median AUC of all the studies was 0.781 (0.550-0.991). In Figure $4 b$, a strong heterogeneity of publication bias is shown due to the low number of studies. Therefore, we evaluated the pooled AUC value using the random effect model, and the pooled AUC was $0.79(0.75-0.83)$. These results confirmed that the copy number of ctDNA (AUC $=0.99$, 95\% CI $=0.98-1.00$ ) [95], combination of metabolites (AUC $=0.96,95 \% \mathrm{CI}=0.94-0.99$ ) [80], and the combination of miRNAs (miR-30a-5p, 205-5p, and 574-3p) (AUC $=0.95,95 \% \mathrm{CI}=0.90-1.00)$ [64] seemed to be a favorable candidate for the early detection of ECs.

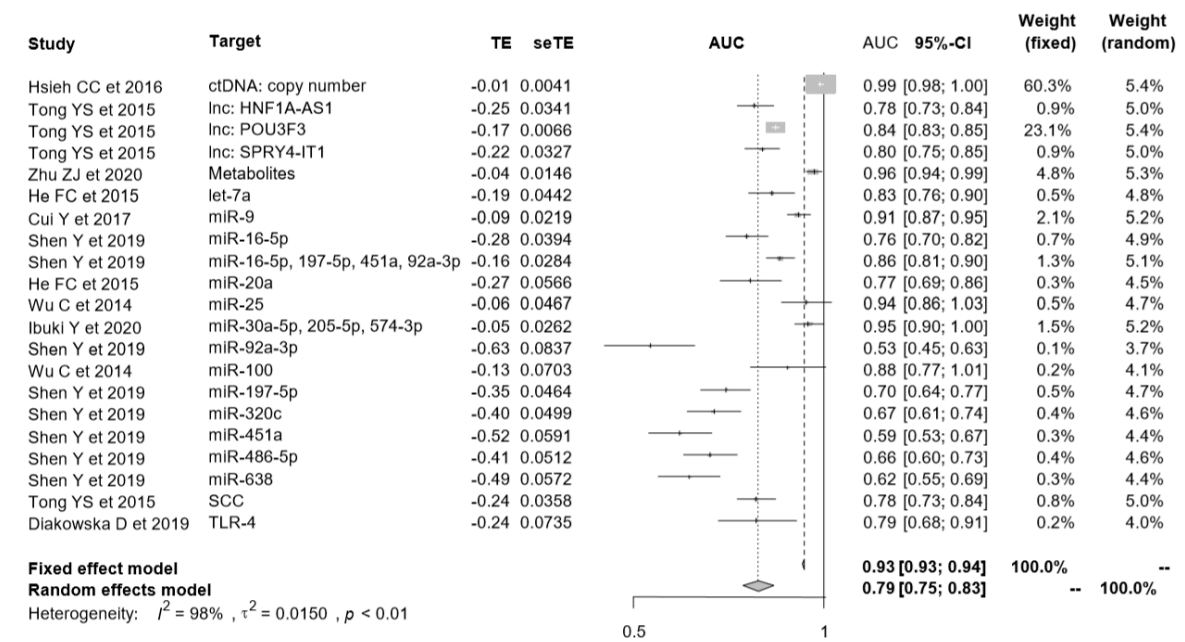

(a)

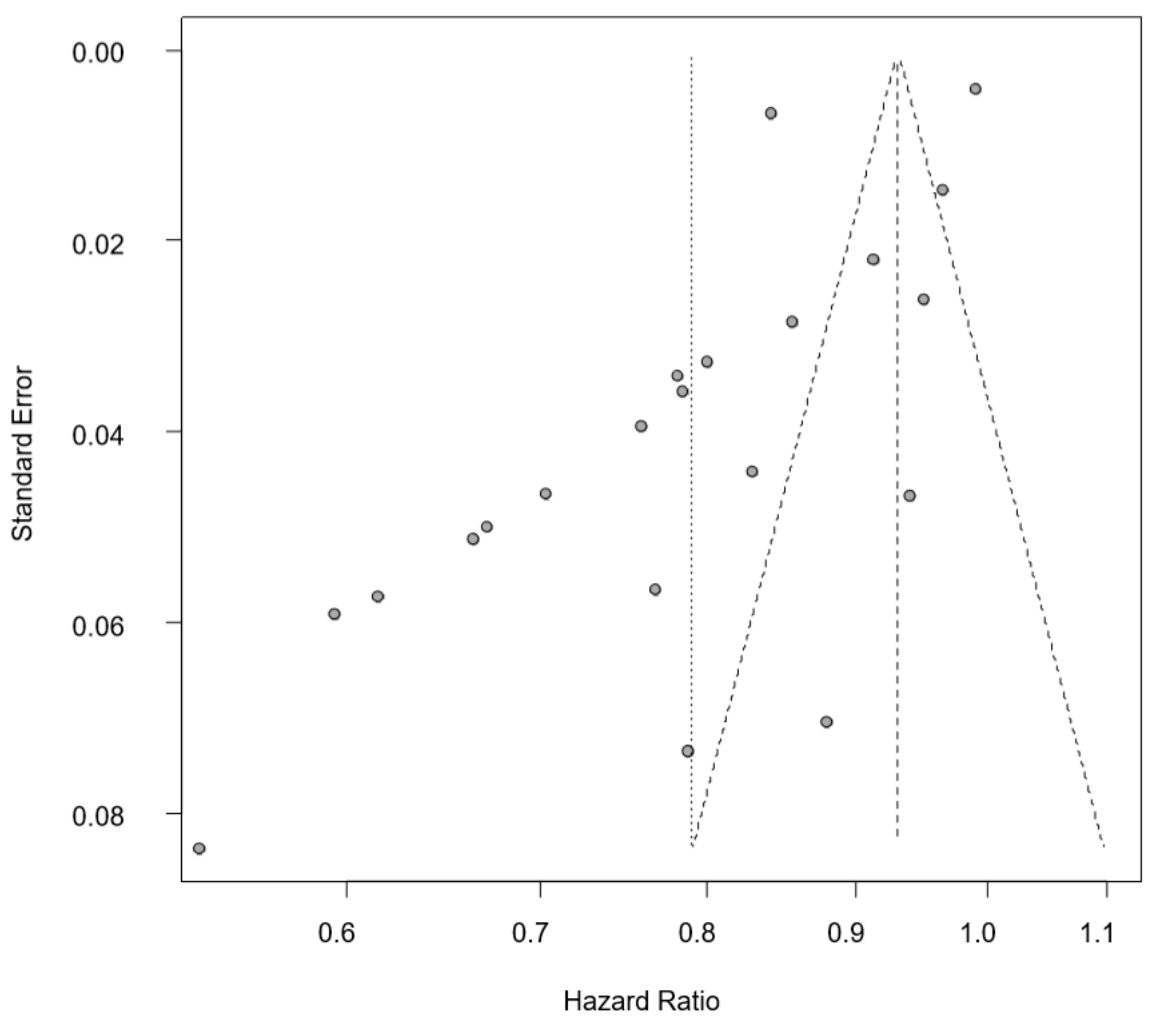

(b)

Figure 4. Cont. 


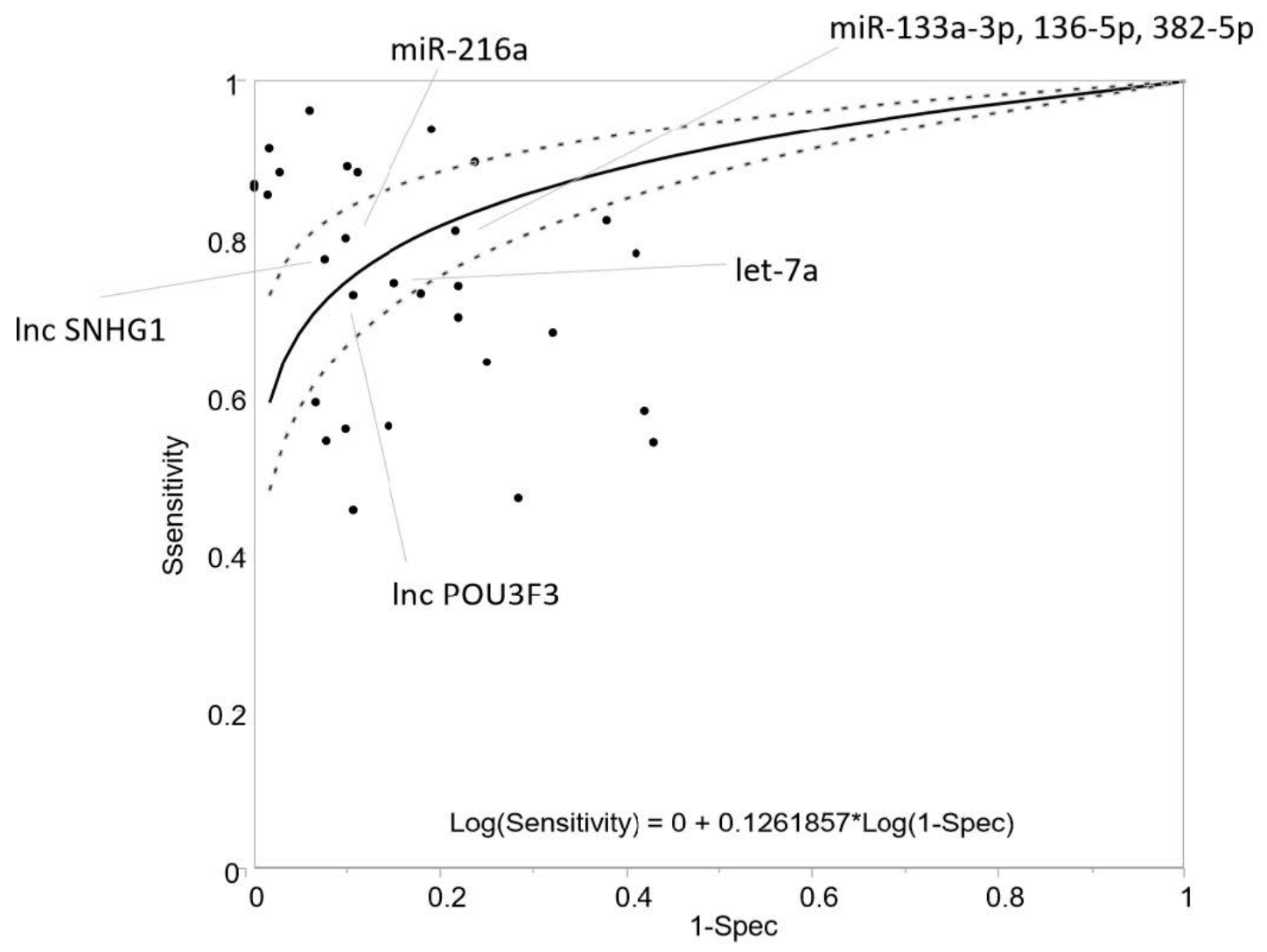

(c)

Figure 4. The diagnostic analysis of liquid biopsies. (a) Forest plot of the area under the curve; (b) funnel plot for the publication bias of (a); (c) the summary receiver operating characteristic (ROC) plot by sensitivity and 1-specificity for each of the molecules. The logarithmic regression curve was found to evaluate the heterogeneity of this analysis.

Next, the derived sensitivity and 1-specificity values from each report (a total of thirty-two molecules from 22 studies [49,50,54,56-58,60-67,72,75,78-80,95-97]) were plotted (Figure 4c). The logarithmic regression curve, with $95 \%$ CIs, was constructed to evaluate the heterogeneity of each diagnostic value, and three molecules (lncSNHG1 [63], miR-216a [67], and a combination of miRNAs (miR16-5p, miR197-5p, and miR92a-3p) [58]) were considered as favorable candidates for the early detection of ECs. 
Table 3. The results of the liquid biopsies for diagnostic evaluation.

\begin{tabular}{|c|c|c|c|c|c|c|c|c|c|c|c|}
\hline $\begin{array}{l}\text { Author, Year, } \\
\text { Country }\end{array}$ & Technology & Molecules & SS & CS & $\begin{array}{l}\text { Age } \\
\text { (Years) }\end{array}$ & Pathology & AUC & Sensitivity & Specificity & $\begin{array}{l}95 \% \text { CIs } \\
\text { (Hi) }\end{array}$ & $\begin{array}{l}\text { 95\% CIs } \\
\text { (Low) }\end{array}$ \\
\hline $\begin{array}{l}\text { Ko et al. [75], } \\
\text { 2020, Korea }\end{array}$ & $\begin{array}{l}\text { ClearCell } \\
\text { CTChip }\end{array}$ & $\begin{array}{l}\text { pan-CK/EpCAM/ } \\
\text { MUC1 baseline }\end{array}$ & 57 & 19 & 63 & ESCC & 0.681 & 0.455 & 0.895 & & \\
\hline $\begin{array}{l}\text { Hsieh et al. [95], } \\
\text { 2016, Taiwan }\end{array}$ & qRT-PCR & $\begin{array}{c}\text { ctDNA: Copy } \\
\text { number }\end{array}$ & 81 & 95 & 60.4 & ESCC & 0.991 & 0.963 & 0.941 & 0.982 & 0.999 \\
\hline $\begin{array}{l}\text { Liao et al. [97], } \\
\text { 2017, China }\end{array}$ & ELISA & $\mathrm{FAP} \alpha$ & 151 & 194 & 62 & ESCC & 0.714 & 0.561 & 0.856 & & \\
\hline $\begin{array}{l}\text { Tong et al. [72], } \\
\text { 2015, China }\end{array}$ & qRT-PCR & lnc POU3F3 & 147 & 23 & - & ESCC & 0.842 & 0.728 & 0.894 & 0.748 & 0.853 \\
\hline $\begin{array}{l}\text { Luoet al. [63], } \\
\text { 2020, China }\end{array}$ & qRT-PCR & lnc SNHG1 & 60 & 60 & - & ESCC & 0.85 & 0.774 & 0.925 & & \\
\hline $\begin{array}{c}\text { Zhang et al. [78], } \\
\text { 2012, China }\end{array}$ & LC-MS & Metabolites & 67 & 34 & - & EAC & 0.92 & 0.89 & 0.9 & & \\
\hline $\begin{array}{c}\text { Xuet al. [79], 2106, } \\
\text { China }\end{array}$ & LC-MS & Metabolites & 62 & 62 & 62 & $\mathrm{EC}$ & 0.981 & 0.913 & 0.984 & & \\
\hline $\begin{array}{c}\text { Zhu et al. [80], } \\
\text { 2020, China }\end{array}$ & LC-MS & Metabolites & 140 & 170 & 60 & ESCC & 0.965 & 0.883 & 0.889 & 0.936 & 0.993 \\
\hline $\begin{array}{c}\text { He et al. [56], 2015, } \\
\text { China }\end{array}$ & qRT-PCR & let-7a & 70 & 40 & 60.5 & ESCC & 0.829 & 0.743 & 0.85 & 0.754 & 0.904 \\
\hline $\begin{array}{l}\text { Cui et al. [57], } \\
\text { 2017, China }\end{array}$ & qRT-PCR & miR-9 & 131 & 131 & - & ESCC & 0.913 & 0.855 & 0.985 & 0.873 & 0.953 \\
\hline $\begin{array}{l}\text { Shen et al. [58], } \\
\text { 2019, China }\end{array}$ & qRT-PCR & $\begin{array}{c}\operatorname{miR}-16-5 p, 197-5 p \\
451 a, 92 a-3 p\end{array}$ & 96 & 78 & 60.1 & ESCC & 0.856 & 0.896 & 0.763 & 0.794 & 0.905 \\
\hline $\begin{array}{l}\text { Zheng et al. [60], } \\
\text { 2019, China }\end{array}$ & qRT-PCR & $\begin{array}{c}\text { miR-16-5p, } 451 a \\
574-5 p\end{array}$ & 23 & 23 & - & ESCC & 0.76 & 0.73 & 0.82 & & \\
\hline $\begin{array}{c}\text { Hirajima et al. [61], } \\
\text { 2013, Japan }\end{array}$ & qRT-PCR & miR-18a & 106 & 54 & - & ESCC & 0.9449 & 0.868 & 1 & & \\
\hline $\begin{array}{c}\text { He et al. [56], 2015, } \\
\text { China }\end{array}$ & qRT-PCR & miR-20a & 70 & 40 & 60.5 & ESCC & 0.767 & 0.643 & 0.75 & 0.677 & 0.857 \\
\hline $\begin{array}{l}\text { Zhang et al. [62], } \\
\text { 2018, China }\end{array}$ & qRT-PCR & miR-21 & 125 & 125 & 63 & ESCC & 0.8 & 0.74 & 0.78 & & \\
\hline $\begin{array}{l}\text { Luo et al. [63], } \\
\text { 2020, China }\end{array}$ & qRT-PCR & miR-21 & 60 & 60 & - & ESCC & 0.928 & 0.883 & 0.973 & & \\
\hline
\end{tabular}


Table 3. Cont

\begin{tabular}{|c|c|c|c|c|c|c|c|c|c|c|c|}
\hline $\begin{array}{l}\text { Author, Year, } \\
\text { Country }\end{array}$ & Technology & Molecules & SS & CS & $\begin{array}{l}\text { Age } \\
\text { (Years) }\end{array}$ & Pathology & AUC & Sensitivity & Specificity & $\begin{array}{l}95 \% \text { CIs } \\
\text { (Hi) }\end{array}$ & $\begin{array}{l}95 \% \text { CIs } \\
\text { (Low) }\end{array}$ \\
\hline $\begin{array}{l}\text { Komatsu et al. } \\
\text { [49], 2016, Japan }\end{array}$ & qRT-PCR & miR-21 & 37 & 20 & - & ESCC & 0.8154 & 0.542 & 0.923 & & \\
\hline $\begin{array}{l}\text { Zhang et al. [62], } \\
\text { 2018, China }\end{array}$ & qRT-PCR & $\operatorname{miR}-25$ & 125 & 125 & 63 & ESCC & 0.55 & 0.54 & 0.57 & & \\
\hline $\begin{array}{l}\text { Wu et al. [50], } \\
\text { 2014, China }\end{array}$ & qRT-PCR & $\operatorname{miR}-25$ & 194 & 94 & - & ESCC & 0.593 & 0.471 & 0.716 & & \\
\hline $\begin{array}{l}\text { Ibuki et al. [64], } \\
\text { 2020, Japan }\end{array}$ & qRT-PCR & $\begin{array}{c}\text { miR-30a-5p } \\
205-5 p, 574-3 p\end{array}$ & 66 & 42 & - & ESCC & 0.95 & 0.938 & 0.81 & 0.91 & 1 \\
\hline $\begin{array}{l}\text { Zhang et al. [62], } \\
\text { 2018, China }\end{array}$ & qRT-PCR & miR-100 & 125 & 125 & 63 & ESCC & 0.58 & 0.58 & 0.58 & & \\
\hline $\begin{array}{l}\text { Bus et al. [65] 2016, } \\
\text { Netherlands }\end{array}$ & qRT-PCR & $\begin{array}{l}\operatorname{miR}-133 a-3 p \\
136-5 p, 382-5 p\end{array}$ & 59 & 15 & 65.8 & EAC & 0.797 & 0.8095 & 0.7838 & & \\
\hline $\begin{array}{l}\text { Pavlov et al. [66], } \\
\text { 2018, Netherlands }\end{array}$ & qRT-PCR & miR-199a-3p, 320e & 17 & 19 & 65.1 & EAC & 0.786 & 0.823 & 0.622 & & \\
\hline $\begin{array}{l}\text { Dong et al. [67], } \\
\text { 2016, China }\end{array}$ & qRT-PCR & miR-216a & 120 & 51 & - & ESCC & 0.877 & 0.8 & 0.902 & & \\
\hline $\begin{array}{l}\text { Dong et al. [67], } \\
\text { 2016, China }\end{array}$ & qRT-PCR & $\mathrm{miR}-216 \mathrm{~b}$ & 120 & 51 & - & ESCC & 0.756 & 0.558 & 0.902 & & \\
\hline $\begin{array}{l}\text { Zhang et al. [62], } \\
\text { 2018, China }\end{array}$ & qRT-PCR & $\mathrm{miR}-223$ & 125 & 125 & 63 & ESCC & 0.73 & 0.68 & 0.68 & & \\
\hline $\begin{array}{l}\text { Zhang et al. [62], } \\
\text { 2018, China }\end{array}$ & qRT-PCR & miR-375 & 125 & 125 & 63 & ESCC & 0.69 & 0.78 & 0.59 & & \\
\hline $\begin{array}{c}\text { Li et al. [54], 2016, } \\
\text { China }\end{array}$ & qRT-PCR & miR-506 & 100 & 40 & 59.2 & ESCC & 0.835 & 0.8636 & 1 & & \\
\hline $\begin{array}{l}\text { Tong et al. [72], } \\
\text { 2015, China }\end{array}$ & qRT-PCR & SCC & 147 & 23 & - & ESCC & 0.784 & 0.592 & 0.935 & 0.727 & 0.841 \\
\hline $\begin{array}{l}\text { Diakowska et al. } \\
\text { [96], 2019, Poland }\end{array}$ & qRT-PCR & TLR-4 & 27 & 38 & - & EAC & 0.787 & 0.7 & 0.78 & 0.661 & 0.909 \\
\hline
\end{tabular}

SS: sample size; CS: control size; AUC: area under curve; CI: confidence interval. 


\section{Discussion}

CTCs are unfavorable cells that are shed into the peripheral blood stream from primary tumors that can develop via metastasis. CTCs have been identified in many cancers, and their malignant behavior has been extensively demonstrated. Several investigators have reported the clinical importance of CTC in managing treatment strategies and predicting prognosis in many solid cancers, including EC. However, compared to other cancers, the clinical impact of CTCs in EC is still unclear due to the lower number of published studies. In the early 2000s, circulating mRNAs in peripheral blood were focused on as a new biomarker for the early diagnosis and prognostic prediction of various cancers. The PCR-based detection of cancer-related genes, such as CEA mRNA, CK mRNA, SCC mRNA, and survivin mRNA, presents good sensitivity in terms of predicting poor prognosis; however, some investigators have noticed that the false positive results from normal epithelial cells might constitute contamination. Since the late 2000s, cytometric methods that could morphologically identify CTCs and count the number of CTCs have been developed and have improved detection specificity. Moreover, we analyzed the genetic and mutational characteristics of each CTC. This has provided a strong contribution to clarifying the metastatic mechanisms of cancer. Although the CellSearch system is the only CTC platform that has been cleared by the FDA, several studies, including our previous study, have demonstrated the clinical utility of CellSearch as a prognostic predictor; however, the detection rate of EC, ranging from $18.0 \%$ to $50.0 \%$, was not as high as we expected. Among the reasons for this result was that the isolation procedures of CellSearch depended on EpCAM expression. Therefore, the other non-EpCAM-dependent platforms have demonstrated a higher detection rate than CellSearch, ranging from $25.6 \%$ to $79.7 \%$. In addition, several investigators have suggested that the measurement of the DNA methylation of cancer-related specific genes and exosomes may be used to detect early cancer or predict prognostic and therapeutic responses for several types of cancer. However, few studies have reported on DNA methylation and exosomes in esophageal cancer, and DNA methylation-based epigenetic signatures are considered to be valuable cancer biomarkers [98-101]. Nevertheless, both cytometric and non-cytometric methods could isolate and analyze cancer-related molecules or cancer cells in the peripheral blood, and these procedures have been called "liquid biopsies", which can be performed repetitively with usual blood sampling.

In the 2010s, owing to the development of scientific technology, comprehensive gene analysis with microarrays was applied to identify circulating cancer-related non-coding RNAs, such as miRNAs and lncRNAs, and NGS was applied to sequence ctDNA. Numerous studies have been reported for many cancers, including EC, and this has become the next standard method for liquid biopsies.

In this meta-analysis, we demonstrated the pooled hazard ratio of the OS and PFS for both cytometric and non-cytometric assays. For OS, the pooled HR of the cytometric assay was relatively higher than that of the non-cytometric assay. For PFS, the pooled HR of the cytometric assay was relatively higher than that of the non-cytometric assay. It seems that the cytometric assay may be a more useful prognostic method than the non-cytometric assay; however, these results depended on the difference of each detection theory and its sensitivity. For both the cytometric and non-cytometric assay, the median CTC detection rates in stages I-II were lower than III-IV. On the other hand, the detection rate for the non-cytometric assay was relatively higher than that of the cytometric assay. These results led the prognostic value of the non-cytometric assay to be relatively lower.

Among the challenging tasks of liquid biopsies is their application to the early diagnosis of cancers. Several investigators have examined the diagnostic value of liquid biopsies for differential diagnosis between pre-cancerous diseases and early EC. Although the pooled AUC for the early diagnosis of EC was $0.79(0.75-0.83)$ in this meta-analysis, it was slightly lower than other cancers; for example, the pooled AUC for hepatocellular carcinoma was 0.87 (0.83-0.89) [102], 0.89 for ovarian cancer [103], and 0.88 for colorectal cancer [104]. There were also two main reasons for this, among which was the presence of heterogeneity for the meta-analysis, owing to the small number of patients in this cohort. The other was that most studies in this review used single molecules as diagnostic predictors. Another cancer meta-analysis, as described above, applied a combination of multiple molecules and 
the copy-number of ctDNA as a comprehensive marker (AUC $=0.99,95 \% \mathrm{CI}=0.98-1.00$ ), as well as a combination of miR-30a-5p, miR-205-5p, and miR-574-3p (AUC $=0.95,95 \%$ CI $=0.90-1.00$ ) [64], demonstrating a favorable diagnostic value. These results suggest that it might be difficult to determine a single definitive biomarker for cancer diagnosis and that exhaustive analysis will be required.

There were some limitations to this study. First, although the meta-analysis required detailed extracted data from as many publications as possible, the number of published studies according to EC and liquid biopsies was fewer than for other cancers. Due to the small number of studies, the heterogeneity became slightly larger than expected. Second, for the non-cytometric assays, differential microarray techniques were used to determine the potential of new biomarkers, and the background of the patient in each study was different. These factors may affect the variability of the prognostic and diagnostic values, even if the same molecules came from other studies. Third, this study did not deal with the pathological differences between ESCC and EAC because of the relatively small number of EAC patients. Therefore, large-scale multicenter studies with matched-pair patients are needed to more accurately estimate the diagnostic and prognostic values of liquid biopsies.

For future perspectives on liquid biopsies, a strong and simple combination of circulating molecules will be anticipated for the clinical management of patients with EC. The early diagnosis of EC using non-invasive liquid biopsies will improve the clinical outcomes of EC, and this will provide a great contribution to reducing healthcare costs. In this meta-analysis, we did not deal with CTM because of lack of sufficient published reports for EC. Umer et al. found that CTM has higher metastatic potential and resistance to apoptosis when compared to their single cell counterparts [105]. As Umer mentioned, several investigators reported the malignant behavior of CTM in other cancers. The analysis of gene mutations, not only in CTCs but also CTM, will be a new candidate for molecular targeted therapy. Alix-Panabieres et al. advocated that CTC-derived cell lines and xenograft models are promising tools for identifying new therapeutic targets and for the development of new medicines [106].

\section{Materials and Methods}

\subsection{Literature Search Strategy}

We searched relevant articles using PubMed and Embase with the keywords "esophageal cancer", "liquid biopsy", and "circulating tumor cells". An additional search with Google Scholar was performed to check for other relevant publications.

\subsection{Inclusion and Exclusion Criteria}

The following inclusion criteria were used: (1) studies were written in English; (2) studies demonstrated prognostic or diagnostic value of CTC in EC; and (3) at least 15 cases were enrolled. The exclusion criteria were the following: (1) meta-analysis, review, commentary, and laboratory articles; or (2) duplicated data reported in other studies.

\subsection{Data Extraction}

Data were retrieved from the included studies by two reviewers (M.D. and A.T.). The extracted data included the following: the first author, publication year, country, number of controls, amount of blood samples, and positive rate of CTCs in each stage. For further analysis, the hazard ratio (HR) and 95\% confidence intervals (CIs) for prognosis, sensitivity, and specificity for diagnosis were retrieved. Two reviewers performed literature selection independently, and any discrepancies were resolved by discussion.

\subsection{Statistical Methods}

Prognostic meta-analysis was performed to evaluate HRs and 95\% CIs by forest plot analysis using the free downloaded software EZR [107]. For diagnostic meta-analysis, the forest plot for the 
AUC and the summary sensitivity and specificity point with summary ROC were estimated using the $\mathrm{JMP}^{\circledR} 11.2 .0$ software.

In the forest plot, the error bars indicate the $95 \%$ confidence interval (CI), the heterogeneity is indicated by $I^{2}$ (intuitive statistic), and P-values less than 0.05 were considered statistically significant. The random effects model was applied to estimate the pooled HR. A funnel plot was used to evaluate publication bias.

\section{Conclusions}

Our meta-analysis confirmed the diagnostic value of liquid biopsies using a molecular combination in esophageal cancer and demonstrated that the presence of CTCs is associated with poor prognosis for both OS and PFS. We believe that this study will act as a milestone for the future development of liquid biopsies alongside esophageal cancer.

Author Contributions: All authors (D.M., T.A., K.O., K.S., M.N., Y.K., S.M., Y.U., T.O. and S.N.) participated in the conceptualization of this project. D.M. and T.A. performed the literature review, and D.M. wrote this manuscript. All authors have read and agreed to the published version of the manuscript.

Funding: This research received no external funding.

Conflicts of Interest: All authors declare no conflicts of interest.

\section{Abbreviations}

CTC Circulating tumor cell;

EC Esophageal cancer;

EAC Esophageal adenocarcinoma;

ESCC Esophageal squamous cell carcinoma;

CT Computed tomography;

PET Positron emission tomography;

CEA Carcinoembryonic antigen;

SCC Squamous cell carcinoma antigen;

F-IHC Fluorescence immunohistochemical staining;

PCR Polymerase chain reaction;

qRT-PCR Quantitative reverse transcription PCR;

NGS Next-generation sequencing;

miRNA Micro RNA;

FDA Food and Drug Administration;

ISET Isolation by size of epithelial tumor cells;

MACS Magnetic cell separation system;

HR Hazard ratio;

CI Confidence interval;

ROC Receiver operating characteristic;

AUC Area under curve;

ELISA Enzyme-linked immunosorbent assay;

LC-MS Liquid chromatography-mass spectrometry;

CK Cytokeratin;

EMT Epithelial-mesenchymal transition;

EpCAM Epithelial cell adhesion molecule;

DAPI Dye 4, 6-diamidino-2-phenylidole dihydrochloride;

CTM Circulating tumor microemboli;

FAST Fluid-assisted separation technique;

ccfDNA Circulating cell free DNA;

ctDNA Circulating tumor DNA;

NMR Nuclear magnetic resonance. 


\section{References}

1. Arnold, M.; Soerjomataram, I.; Ferlay, J.; Forman, D. Global incidence of oesophageal cancer by histological subtype in 2012. Gut 2014, 64, 381-387. [CrossRef]

2. $\quad$ Rice, T.W.; Apperson-Hansen, C.; DiPaola, L.M.; Semple, M.E.; Lerut, T.E.M.R.; Orringer, M.B.; Chen, L.-Q.; Hofstetter, W.L.; Smithers, B.M.; Rusch, V.W.; et al. Worldwide Esophageal Cancer Collaboration: Clinical staging data. Dis. Esophagus 2016, 29, 707-714. [CrossRef] [PubMed]

3. Global Burden of Disease Cancer Collaboration; Fitzmaurice, C.; Allen, C.; Barber, R.M.; Barregard, L.; Bhutta, Z.A.; Brenner, H.; Dicker, D.J.; Chimed-Orchir, O.; Dandona, R.; et al. Global, Regional, and National Cancer Incidence, Mortality, Years of Life Lost, Years Lived With Disability, and Disability-Adjusted Life-years for 32 Cancer Groups, 1990 to 2015. JAMA Oncol. 2017, 3, 524-548. [CrossRef]

4. Kosugi, S.-I.; Nishimaki, T.; Kanda, T.; Nakagawa, S.; Ohashi, M.; Hatakeyama, K. Clinical Significance of Serum Carcinoembryonic Antigen, Carbohydrate Antigen 19-9, and Squamous Cell Carcinoma Antigen Levels in Esophageal Cancer Patients. World J. Surg. 2004, 28, 680-685. [CrossRef] [PubMed]

5. Ashworth, T.R. A case of cancer in which cells similar to those in the tumors were seen in the blood after death. Aust. Med. J. 1869, 14, 146-149.

6. Allard, W.J. Tumor Cells Circulate in the Peripheral Blood of All Major Carcinomas but not in Healthy Subjects or Patients with Nonmalignant Diseases. Clin. Cancer Res. 2004, 10, 6897-6904. [CrossRef]

7. Nakashima, S.; Natsugoe, S.; Matsumoto, M.; Miyazono, F.; Nakajo, A.; Uchikura, K.; Tokuda, K.; Ishigami, S.; Baba, M.; Takao, S.; et al. Clinical significance of circulating tumor cells in blood by molecular detection and tumor markers in esophageal cancer. Surgery 2003, 133, 162-169. [CrossRef] [PubMed]

8. Kaganoi, J.; Shimada, Y.; Kano, M.; Okumura, T.; Watanabe, G.; Imamura, M. Detection of circulating oesophageal squamous cancer cells in peripheral blood and its impact on prognosis. Br. J. Surg. 2004, 91, 1055-1060. [CrossRef]

9. Liu, Z.; Jiang, M.; Yan, F.; Xu, L.; Zhong, S.-L.; Ju, H. Multipoint quantification of multimarker genes in peripheral blood and micrometastasis characteristic in peri-operative esophageal cancer patients. Cancer Lett. 2008, 261, 46-54. [CrossRef]

10. Cristofanilli, M.; Budd, G.T.; Ellis, M.J.; Stopeck, A.; Matera, J.; Miller, M.C.; Reuben, J.M.; Doyle, G.V.; Allard, W.J.; Terstappen, L.W.; et al. Circulating Tumor Cells, Disease Progression, and Survival in Metastatic Breast Cancer. N. Engl. J. Med. 2004, 351, 781-791. [CrossRef]

11. Cohen, S.J.; Punt, C.J.A.; Iannotti, N.; Saidman, B.H.; Sabbath, K.D.; Gabrail, N.Y.; Picus, J.; Morse, M.; Mitchell, E.; Miller, M.C.; et al. Relationship of Circulating Tumor Cells to Tumor Response, Progression-Free Survival, and Overall Survival in Patients With Metastatic Colorectal Cancer. J. Clin. Oncol. 2008, 26, 3213-3221. [CrossRef] [PubMed]

12. De Bono, J.S.; Scher, H.I.; Montgomery, R.B.; Parker, C.; Miller, M.C.; Tissing, H.; Doyle, G.; Terstappen, L.W.; Pienta, K.J.; Raghavan, D. Circulating Tumor Cells Predict Survival Benefit from Treatment in Metastatic Castration-Resistant Prostate Cancer. Clin. Cancer Res. 2008, 14, 6302-6309. [CrossRef] [PubMed]

13. Matsushita, D.; Uenosono, Y.; Arigami, T.; Yanagita, S.; Nishizono, Y.; Hagihara, T.; Hirata, M.; Haraguchi, N.; Arima, H.; Kijima, Y.; et al. Clinical Significance of Circulating Tumor Cells in Peripheral Blood of Patients with Esophageal Squamous Cell Carcinoma. Ann. Surg. Oncol. 2015, 22, 3674-3680. [CrossRef]

14. Vona, G.; Sabile, A.; Louha, M.; Sitruk, V.; Romana, S.; Schütze, K.; Capron, F.; Franco, D.; Pazzagli, M.; Vekemans, M.; et al. Isolation by Size of Epithelial Tumor Cells. Am. J. Pathol. 2000, 156, 57-63. [CrossRef]

15. DeSitter, I.; Guerrouahen, B.S.; Benali-Furet, N.; Wechsler, J.; Jänne, P.A.; Kuang, Y.; Yanagita, M.; Wang, L.; Berkowitz, J.A.; Distel, R.J.; et al. A new device for rapid isolation by size and characterization of rare circulating tumor cells. Anticancer Res. 2011, 31, 427-441.

16. Bobek, V.; Matkowski, R.; Gürlich, R.; Grabowski, K.; Szelachowska, J.; Lischke, R.; Schutzner, J.; Harustiak, T.; Pazdro, A.; Rzechonek, A.; et al. Cultivation of circulating tumor cells in esophageal cancer. Folia Histochem. Cytobiol. 2014, 52, 171-177. [CrossRef]

17. Miltenyi, S.; Müller, W.; Weichel, W.; Radbruch, A. High gradient magnetic cell separation with MACS. Cytometry 1990, 11, 231-238. [CrossRef]

18. Nagrath, S.; Sequist, L.V.; Maheswaran, S.; Bell, D.W.; Irimia, D.; Ulkus, L.; Smith, M.R.; Kwak, E.L.; Digumarthy, S.R.; Muzikansky, A.; et al. Isolation of rare circulating tumour cells in cancer patients by microchip technology. Nat. Cell Biol. 2007, 450, 1235-1239. [CrossRef] 
19. Harb, W.; Fan, A.; Tran, T.; Danila, D.C.; Keys, D.; Schwartz, M.; Ionescu-Zanetti, C. Mutational Analysis of Circulating Tumor Cells Using a Novel Microfluidic Collection Device and qPCR Assay. Transl. Oncol. 2013, 6, 528-538. [CrossRef] [PubMed]

20. He, W.; Kularatne, S.A.; Kalli, K.R.; Prendergast, F.G.; Amato, R.J.; Klee, G.G.; Hartmann, L.C.; Low, P.S. Quantitation of circulating tumor cells in blood samples from ovarian and prostate cancer patients using tumor-specific fluorescent ligands. Int. J. Cancer 2008, 123, 1968-1973. [CrossRef]

21. Zhu, Z.; Qiu, S.; Shao, K.; Hou, Y. Progress and challenges of sequencing and analyzing circulating tumor cells. Cell Biol. Toxicol. 2017, 34, 405-415. [CrossRef]

22. Onidani, K.; Shoji, H.; Kakizaki, T.; Yoshimoto, S.; Okaya, S.; Miura, N.; Sekikawa, S.; Furuta, K.; Lim, C.T.; Shibahara, T.; et al. Monitoring of cancer patients via next-generation sequencing of patient-derived circulating tumor cells and tumor DNA. Cancer Sci. 2019, 110, 2590-2599. [CrossRef]

23. Yu, J.; Leung, W.K.; Ebert, M.P.A.; Ng, E.K.W.; Go, M.Y.Y.; Wang, H.B.; Chung, S.C.S.; Malfertheiner, P.; Sung, J.J. Increased expression of survivin in gastric cancer patients and in first degree relatives. Br. J. Cancer 2002, 87, 91-97. [CrossRef]

24. Hiraiwa, K.; Takeuchi, H.; Hasegawa, H.; Saikawa, Y.; Suda, K.; Ando, T.; Kumagai, K.; Irino, T.; Yoshikawa, T.; Matsuda, S.; et al. Clinical Significance of Circulating Tumor Cells in Blood from Patients with Gastrointestinal Cancers. Ann. Surg. Oncol. 2008, 15, 3092-3100. [CrossRef]

25. Konczalla, L.; Ghadban, T.; Effenberger, K.E.; Wöstemeier, A.; Riethdorf, S.; Uzunoglu, F.G.; Izbicki, J.R.; Pantel, K.; Bockhorn, M.; Reeh, M. Prospective Comparison of the Prognostic Relevance of Circulating Tumor Cells in Blood and Disseminated Tumor Cells in Bone Marrow of a Single Patient's Cohort with Esophageal Cancer. Ann. Surg. 2019. [CrossRef] [PubMed]

26. Reeh, M.; Harms-Effenberger, K.; Koenig, A.M.; Riethdorf, S.; Eichstädt, D.; Vettorazzi, E.; Uzunoglu, F.G.; Vashist, Y.K.; Izbicki, J.R.; Pantel, K.; et al. Circulating Tumor Cells as a Biomarker for Preoperative Prognostic Staging in Patients with Esophageal Cancer. Ann. Surg. 2015, 261, 1124-1130. [CrossRef] [PubMed]

27. Qiao, Y.; Li, J.; Shi, C.; Wang, W.; Qu, X.; Xiong, M.; Sun, Y.; Li, D.; Zhao, X.; Zhang, D. Prognostic value of circulating tumor cells in the peripheral blood of patients with esophageal squamous cell carcinoma. Onco Targets Ther. 2017, 10, 1363-1373. [CrossRef] [PubMed]

28. Li, Y.; Ma, G.; Zhao, P.; Fu, R.; Gao, L.; Jiang, X.; Hu, P.; Ren, T.; Wu, Y.; Wang, Z.; et al. Improvement of sensitive and specific detection of circulating tumor cells using negative enrichment and immunostaining-FISH. Clin. Chim. Acta 2018, 485, 95-102. [CrossRef] [PubMed]

29. Zhang, Y.; Li, J.; Wang, L.; Meng, P.; Zhao, J.; Han, P.; Xia, J.; Xu, J.; Wang, L.; Shen, F.; et al. Clinical significance of detecting circulating tumor cells in patients with esophageal squamous cell carcinoma by EpCAM-independent enrichment and immunostaining-fluorescence in situ hybridization. Mol. Med. Rep. 2019, 20, 1551-1560. [CrossRef]

30. Baccelli, I.; Schneeweiss, A.; Riethdorf, S.; Stenzinger, A.; Schillert, A.; Vogel, V.; Klein, C.; Saini, M.; Bäuerle, T.; Wallwiener, M.; et al. Identification of a population of blood circulating tumor cells from breast cancer patients that initiates metastasis in a xenograft assay. Nat. Biotechnol. 2013, 31, 539-544. [CrossRef]

31. Sollier, E.; Go, D.E.; Che, J.; Gossett, D.R.; O’Byrne, S.; Weaver, W.M.; Kummer, N.; Rettig, M.; Goldman, J.; Nickols, N.; et al. Size-selective collection of circulating tumor cells using Vortex technology. Lab Chip 2014, 14, 63-77. [CrossRef]

32. Zhao, Y.; Zhao, S.; Chen, Y.; Dong, X.; Peng, C.; Sun, Q.; Shan, L.; Wang, Z.; Zhao, X. Isolation of circulating tumor cells in patients undergoing surgery for esophageal cancer and a specific confirmation method. Oncol. Lett. 2019, 4, 3817-3825. [CrossRef]

33. Ohnaga, T.; Shimada, Y.; Takata, K.; Obata, T.; Okumura, T.; Nagata, T.; Kishi, H.; Muraguchi, A.; Tsukada, K. Capture of esophageal and breast cancer cells with polymeric microfluidic devices for CTC isolation. Mol. Clin. Oncol. 2016, 4, 599-602. [CrossRef]

34. Chudasama, D.Y.; Freydina, D.V.; Freidin, M.B.; Leung, M.; Fernandez, A.M.; Rice, A.; Nicholson, A.G.; Karteris, E.; Anikin, V.; Lim, E. Inertia based microfluidic capture and characterisation of circulating tumour cells for the diagnosis of lung cancer. Ann. Transl. Med. 2016, 4, 480. [CrossRef]

35. Karabacak, N.M.; Spuhler, P.S.; Fachin, F.; Lim, E.J.; Pai, V.; Ozkumur, E.; Martel, J.M.; Kojic, N.; Smith, B.A.H.; Chen, P.-I.; et al. Microfluidic, marker-free isolation of circulating tumor cells from blood samples. Nat. Protoc. 2014, 9, 694-710. [CrossRef] 
36. Earhart, C.M.; Hughes, C.E.; Gaster, R.S.; Ooi, C.C.; Wilson, R.J.; Zhou, L.Y.; Humke, E.W.; Xu, L.; Wong, D.J.; Willingham, S.B.; et al. Isolation and mutational analysis of circulating tumor cells from lung cancer patients with magnetic sifters and biochips. Lab Chip 2014, 14, 78-88. [CrossRef]

37. Choi, M.K.; Kim, G.H.; I, H.; Park, S.J.; Lee, M.W.; Lee, B.E.; Park, D.Y.; Cho, Y.-K. Circulating tumor cells detected using fluid-assisted separation technique in esophageal squamous cell carcinoma. J. Gastroenterol. Hepatol. 2018, 34, 552-560. [CrossRef]

38. Ismail, M.M.; James, C.; Webbe, G. The enzyme linked immunosorbent assay (ELISA) for the determination of circulating antigen and antibody in Schistosoma haematobium-infected baboons. Trans. R. Soc. Trop. Med. Hyg. 1981, 75, 542-548. [CrossRef]

39. Nozoe, T.; Maehara, Y.; Sugimachi, K. Preoperative sorting of circulating T lymphocytes in patients with esophageal squamous cell carcinoma: Its prognostic significance. World J. Gastroenterol. 2005, 11, 6689-6693. [CrossRef]

40. Kimura, H.; Kato, H.; Tanaka, N.; Inose, T.; Faried, A.; Sohda, M.; Nakajima, M.; Fukai, Y.; Miyazaki, T.; Masuda, N.; et al. Preoperative serum vascular endothelial growth factor-C (VEGF-C) levels predict recurrence in patients with esophageal cancer. Anticancer Res. 2008, 28, 165-169.

41. Curran, M.A.; Montalvo, W.; Yagita, H.; Allison, J.P. PD-1 and CTLA-4 combination blockade expands infiltrating $\mathrm{T}$ cells and reduces regulatory $\mathrm{T}$ and myeloid cells within B16 melanoma tumors. Proc. Natl. Acad. Sci. USA 2010, 107, 4275-4280. [CrossRef]

42. Setoyama, T.; Natsugoe, S.; Okumura, H.; Matsumoto, M.; Uchikado, Y.; Ishigami, S.; Owaki, T.; Takao, S.; Aikou, T. Carcinoembryonic Antigen Messenger RNA Expression in Blood Predicts Recurrence in Esophageal Cancer. Clin. Cancer Res. 2006, 12, 5972-5977. [CrossRef]

43. Srinivasula, S.M.; Ashwell, J.D. IAPs: What's in a Name? Mol. Cell 2008, 30, 123-135. [CrossRef]

44. Hoffmann, A.-C.; Vallböhmer, D.; Grimminger, P.P.; Metzger, R.; Prenzel, K.L.; Hoelscher, A.H.; Brabender, J. Preoperative survivin mRNA detection in peripheral blood is an independent predictor of outcome in esophageal carcinoma. Pharmacogenomics 2010, 11, 341-347. [CrossRef]

45. Lambrechts, A.; Bosma, A.; Klaver, S.; Top, B.; Perebolte, L.; Veer, L.J.V.T.; Rodenhuis, S. Comparison of immunocytochemistry, reverse transcriptase polymerase chain reaction, and nucleic acid sequence-based amplification for the detection of circulating breast cancer cells. Breast Cancer Res. Treat. 1999, 56, $217-229$. [CrossRef]

46. Mitchell, P.S.; Parkin, R.K.; Kroh, E.M.; Fritz, B.R.; Wyman, S.K.; Pogosova-Agadjanyan, E.L.; Peterson, A.; Noteboom, J.; O'Briant, K.C.; Allen, A.; et al. Circulating microRNAs as stable blood-based markers for cancer detection. Proc. Natl. Acad. Sci. USA 2008, 105, 10513-10518. [CrossRef]

47. Li, J.; Li, M.; Gao, F.; Ge, X. Serum microRNA-15a level acts as a potential diagnostic and prognostic biomarker for human esophageal squamous cell carcinoma. Cancer Biomark. 2017, 18, 11-17. [CrossRef]

48. Lv, H.; He, Z.; Wang, H.; Du, T.; Pang, Z. Differential expression of miR-21 and miR-75 in esophageal carcinoma patients and its clinical implication. Am. J. Transl. Res. 2016, 8, 3288-3298.

49. Komatsu, S.; Ichikawa, D.; Kawaguchi, T.; Miyamae, M.; Okajima, W.; Ohashi, T.; Imamura, T.; Kiuchi, J.; Konishi, H.; Shiozaki, A.; et al. Circulating miR-21 as an independent predictive biomarker for chemoresistance in esophageal squamous cell carcinoma. Am. J. Cancer Res. 2016, 6, 1511-1523.

50. Wu, C.; Li, M.; Hu, C.; Duan, H. Clinical significance of serum miR-223, miR-25 and miR-375 in patients with esophageal squamous cell carcinoma. Mol. Biol. Rep. 2014, 41, 1257-1266. [CrossRef]

51. Gu, J.; Zhang, J.; Zheng, L.; Ajani, J.A.; Wu, X.; Ye, Y. Serum miR-331-3p predicts tumor recurrence in esophageal adenocarcinoma. Sci. Rep. 2018, 8, 14006. [CrossRef]

52. Tanaka, K.; Miyata, H.; Yamasaki, M.; Sugimura, K.; Takahashi, T.; Kurokawa, Y.; Nakajima, K.; Takiguchi, S.; Mori, M.; Doki, Y. Circulating miR-200c Levels Significantly Predict Response to Chemotherapy and Prognosis of Patients Undergoing Neoadjuvant Chemotherapy for Esophageal Cancer. Ann. Surg. Oncol. 2013, 20, 607-615. [CrossRef]

53. Zhai, R.; Wei, Y.; Su, L.; Liu, G.; Kulke, M.H.; Wain, J.C.; Christiani, D.C. Whole-miRNome profiling identifies prognostic serum miRNAs in esophageal adenocarcinoma: The influence of Helicobacter pylori infection status. Carcinogenesis 2014, 36, 87-93. [CrossRef]

54. Li, S.-P.; Su, H.-X.; Zhao, D.; Guan, Q.-L. Plasma miRNA-506 as a Prognostic Biomarker for Esophageal Squamous Cell Carcinoma. Med. Sci. Monit. 2016, 22, 2195-2201. [CrossRef] 
55. Guan, S.; Wang, C.; Chen, X.; Liu, B.; Tan, B.; Liu, F.; Wang, D.; Han, L.; Wang, L.; Huang, X.; et al. MiR-613: A novel diagnostic and prognostic biomarker for patients with esophageal squamous cell carcinoma. Tumor Biol. 2015, 37, 4383-4391. [CrossRef]

56. He, F.; Meng, W.-W.; Qu, Y.-H.; Zhou, M.-X.; He, J.; Lv, P.; Ming, L. Expression of circulating microRNA-20a and let-7a in esophageal squamous cell carcinoma. World J. Gastroenterol. 2015, 21, 4660-4665. [CrossRef]

57. Cui, Y.; Xue, Y.; Dong, S.; Zhang, P. Plasma microRNA-9 as a diagnostic and prognostic biomarker in patients with esophageal squamous cell carcinoma. J. Int. Med. Res. 2017, 45, 1310-1317. [CrossRef]

58. Shen, Y.; Ding, Y.; Ma, Q.; Zhao, L.; Guo, X.; Shao, Y.; Niu, C.; He, Y.; Zhang, F.; Zheng, D.; et al. Identification of Novel Circulating miRNA Biomarkers for the Diagnosis of Esophageal Squamous Cell Carcinoma and Squamous Dysplasia. Cancer Epidemiol. Biomark. Prev. 2019, 28, 1212-1220. [CrossRef]

59. Chiam, K.; Wang, T.; Watson, D.I.; Mayne, G.C.; Irvine, T.S.; Bright, T.F.; Smith, L.; White, I.A.; Bowen, J.M.; Keefe, D.; et al. Circulating Serum Exosomal miRNAs As Potential Biomarkers for Esophageal Adenocarcinoma. J. Gastrointest. Surg. 2015, 19, 1208-1215. [CrossRef]

60. Zheng, D.; Ding, Y.; Ma, Q.; Zhao, L.; Guo, X.; Shen, Y.; He, Y.; Wei, W.; Liu, F. Identification of Serum MicroRNAs as Novel Biomarkers in Esophageal Squamous Cell Carcinoma Using Feature Selection Algorithms. Front. Oncol. 2019, 8, 674. [CrossRef]

61. Hirajima, S.; Komatsu, S.; Ichikawa, D.; Takeshita, H.; Konishi, H.; Shiozaki, A.; Morimura, R.; Tsujiura, M.; Nagata, H.; Kawaguchi, T.; et al. Clinical impact of circulating miR-18a in plasma of patients with oesophageal squamous cell carcinoma. Br. J. Cancer 2013, 108, 1822-1829. [CrossRef]

62. Zhang, L.; Dong, B.; Ren, P.; Ye, H.; Shi, J.; Qin, J.; Wang, K.; Wang, P.; Zhang, J. Circulating plasma microRNAs in the detection of esophageal squamous cell carcinoma. Oncol. Lett. 2018, 16, 3303-3318. [CrossRef] [PubMed]

63. Cheng, L.; Huang, Z.; Lv, H.; Wang, Y.; Sun, W.; Sun, X. Up-Regulation of MicroRNA-21 Indicates Poor Prognosis and Promotes Cell Proliferation in Esophageal Squamous Cell Carcinoma via Upregulation of lncRNA SNHG1. Cancer Manag. Res. 2020, 12, 1-14. [CrossRef]

64. Ibuki, Y.; Nishiyama, Y.; Tsutani, Y.; Emi, M.; Hamai, Y.; Okada, M.; Tahara, H. Circulating microRNA/isomiRs as novel biomarkers of esophageal squamous cell carcinoma. PLoS ONE 2020, 15, e231116. [CrossRef]

65. Bus, P.; Kestens, C.; Kate, F.J.W.T.; Peters, W.; Drenth, J.P.H.; Roodhart, J.M.L.; Siersema, P.D.; Van Baal, J.W.P.M. Profiling of circulating microRNAs in patients with Barrett's esophagus and esophageal adenocarcinoma. J. Gastroenterol. 2015, 51, 560-570. [CrossRef] [PubMed]

66. Pavlov, K.; Kluiver, J.; Meijer, C.; Ek, W.B.-V.; Kruyt, F.A.E.; Karrenbeld, A.; Kleibeuker, J.H.; Peters, F.T.M.; Berg, A.V.D. Circulating miRNAs in patients with Barrett's esophagus, high-grade dysplasia and esophageal adenocarcinoma. J. Gastrointest. Oncol. 2018, 9, 1150-1156. [CrossRef]

67. Dong, S.; Yin, H.; Dong, C.; Sun, K.; Lv, P.; Meng, W.; Ming, L.; He, F. Predictive Value of Plasma MicroRNA-216a/b in the Diagnosis of Esophageal Squamous Cell Carcinoma. Dis. Mark. 2016, 2016, 1857067. [CrossRef]

68. Huang, Z.; Zhang, L.; Zhu, D.; Shan, X.; Zhou, X.; Qi, L.-W.; Wu, L.; Zhu, J.; Cheng, W.; Zhang, H.; et al. A novel serum microRNA signature to screen esophageal squamous cell carcinoma. Cancer Med. 2016, 6, 109-119. [CrossRef] [PubMed]

69. Zhang, K.; Wu, X.; Wang, J.; Lopez, J.; Zhou, W.; Yang, L.; Wang, S.E.; Raz, D.J.; Kim, J.Y. Circulating miRNA profile in esophageal adenocarcinoma. Am. J. Cancer Res. 2016, 6, 2713-2721.

70. Perkel, J.M. Visiting “Noncodarnia”. Biotechniques 2013, 54, 301-304. [CrossRef]

71. Qi, P.; Du, X. The long non-coding RNAs, a new cancer diagnostic and therapeutic gold mine. Mod. Pathol. 2012, 26, 155-165. [CrossRef] [PubMed]

72. Tong-Xin, Y.; Wang, X.-W.; Zhou, X.-L.; Liu, Z.-H.; Yang, T.-X.; Shi, W.-H.; Xie, H.-W.; Lv, J.; Wu, Q.-Q.; Cao, X.-F. Identification of the long non-coding RNA POU3F3 in plasma as a novel biomarker for diagnosis of esophageal squamous cell carcinoma. Mol. Cancer 2015, 14, 3. [CrossRef] [PubMed]

73. Hu, H.-B.; Jie, H.-Y.; Zheng, X.-X. Three Circulating LncRNA Predict Early Progress of Esophageal Squamous Cell Carcinoma. Cell. Physiol. Biochem. 2016, 40, 117-125. [CrossRef] [PubMed]

74. Mandel, P.; Metais, P. Les acides nucléiques du plasma sanguin chez l'homme. CR Seances Soc. Biol. Fil. 1948, 142, 241. 
75. Ko, J.M.Y.; Ng, H.Y.; Lam, K.-O.; Chiu, K.W.-H.; Kwong, D.L.W.; Lo, A.W.; Wong, J.C.; Lin, R.C.W.; Fong, H.C.H.; Li, J.Y.K.; et al. Liquid Biopsy Serial Monitoring of Treatment Responses and Relapse in Advanced Esophageal Squamous Cell Carcinoma. Cancers 2020, 12, 1352. [CrossRef]

76. Forshew, T.; Murtaza, M.; Parkinson, C.; Gale, D.; Tsui, D.W.Y.; Kaper, F.; Dawson, S.-J.; Piskorz, A.M.; Jimenez-Linan, M.; Bentley, D.; et al. Noninvasive Identification and Monitoring of Cancer Mutations by Targeted Deep Sequencing of Plasma DNA. Sci. Transl. Med. 2012, 4, 136ra68. [CrossRef]

77. Grölz, D.; Hauch, S.; Schlumpberger, M.; Guenther, K.; Voss, T.; Sprenger-Haussels, M.; Oelmüller, U. Liquid Biopsy Preservation Solutions for Standardized Pre-Analytical Workflows-Venous Whole Blood and Plasma. Curr. Pathobiol. Rep. 2018, 6, 275-286. [CrossRef]

78. Zhang, J.; Bowers, J.; Liu, L.; Wei, S.; Gowda, G.A.N.; Hammoud, Z.; Raftery, D. Esophageal Cancer Metabolite Biomarkers Detected by LC-MS and NMR Methods. PLoS ONE 2012, 7, e30181. [CrossRef]

79. Xu, J.; Chen, Y.; Zhang, R.; He, J.; Song, Y.; Wang, J.; Wang, H.; Wang, L.; Zhan, Q.; Abliz, Z. Global metabolomics reveals potential urinary biomarkers of esophageal squamous cell carcinoma for diagnosis and staging. Sci. Rep. 2016, 6, 35010. [CrossRef]

80. Zhu, Z.-J.; Qi, Z.; Zhang, J.; Xue, W.-H.; Li, L.-F.; Shen, Z.-B.; Li, Z.-Y.; Yuan, Y.-L.; Wang, W.-B.; Zhao, J. Untargeted Metabolomics Analysis of Esophageal Squamous Cell Carcinoma Discovers Dysregulated Metabolic Pathways and Potential Diagnostic Biomarkers. J. Cancer 2020, 11, 3944-3954. [CrossRef]

81. Aretz, I.; Meierhofer, D. Advantages and Pitfalls of Mass Spectrometry Based Metabolome Profiling in Systems Biology. Int. J. Mol. Sci. 2016, 17, 632. [CrossRef]

82. Woestemeier, A.; Harms-Effenberger, K.; Karstens, K.-F.; Konczalla, L.; Ghadban, T.; Uzunoglu, F.G.; Izbicki, J.R.; Bockhorn, M.; Pantel, K.; ReehMichael, M. Clinical Relevance of Circulating Tumor Cells in Esophageal Cancer Detected by a Combined MACS Enrichment Method. Cancers 2020, 12, 718. [CrossRef] [PubMed]

83. Tanaka, M.; Takeuchi, H.; Osaki, Y.; Hiraiwa, K.; Nakamura, R.; Oyama, T.; Takahashi, T.; Wada, N.; Kawakubo, H.; Saikawa, Y.; et al. Prognostic significance of circulating tumor cells in patients with advanced esophageal cancer. Esophagus 2014, 12, 352-359. [CrossRef]

84. Pernot, S.; Badoual, C.; Terme, M.; Castan, F.; Cazes, A.; Bouche, O.; Bennouna, J.; Francois, E.; Ghiringhelli, F.; De La Fouchardiere, C.; et al. Dynamic evaluation of circulating tumour cells in patients with advanced gastric and oesogastric junction adenocarcinoma: Prognostic value and early assessment of therapeutic effects. Eur. J. Cancer 2017, 79, 15-22. [CrossRef]

85. Brungs, D.; Lynch, D.; Luk, A.W.; Minaei, E.; Ranson, M.; Aghmesheh, M.; Vine, K.L.; Carolan, M.; Jaber, M.; De Souza, P.; et al. Cryopreservation for delayed circulating tumor cell isolation is a valid strategy for prognostic association of circulating tumor cells in gastroesophageal cancer. World J. Gastroenterol. 2018, 24, 810-818. [CrossRef]

86. Han, L.; Li, Y.-J.; Zhang, W.-D.; Song, P.-P.; Li, H.; Li, S. Clinical significance of tumor cells in the peripheral blood of patients with esophageal squamous cell carcinoma. Med. Baltim. 2019, 98, e13921. [CrossRef] [PubMed]

87. Chen, W.; Li, Y.; Yuan, D.; Peng, Y.; Qin, J. Practical value of identifying circulating tumor cells to evaluate esophageal squamous cell carcinoma staging and treatment efficacy. Thorac. Cancer 2018, 9, 956-966. [CrossRef] [PubMed]

88. Jiao, W.; Xu, J.; Zheng, J.; Shen, Y.; Lin, L.; Li, J. Elevation of circulating big endothelin-1: An independent prognostic factor for tumor recurrence and survival in patients with esophageal squamous cell carcinoma. BMC Cancer 2008, 8, 334. [CrossRef] [PubMed]

89. Blanchard, P.; Quero, L.; Pacault, V.; Schlageter, M.-H.; Baruch-Hennequin, V.; Hennequin, C. Prognostic significance of anti-p53 and anti-KRas circulating antibodies in esophageal cancer patients treated with chemoradiotherapy. BMC Cancer 2012, 12, 119. [CrossRef] [PubMed]

90. Cao, M.; Yie, S.-M.; Wu, S.-M.; Chen, S.; Lou, B.; He, X.; Ye, S.-R.; Xie, K.; Rao, L.; Gao, E.; et al. Detection of survivin-expressing circulating cancer cells in the peripheral blood of patients with esophageal squamous cell carcinoma and its clinical significance. Clin. Exp. Metastasis 2009, 26, 751-758. [CrossRef]

91. He, X.; Xu, X.; Zhu, G.; Ye, H. Circulating uPA as a potential prognostic biomarker for resectable esophageal squamous cell carcinoma. Med. Baltim. 2019, 98, e14717. [CrossRef] [PubMed] 
92. Tanaka, K.; Yano, M.; Motoori, M.; Kishi, K.; Miyashiro, I.; Shingai, T.; Gotoh, K.; Noura, S.; Takahashi, H.; Ohue, M.; et al. CEA-Antigen and SCC-Antigen mRNA Expression in Peripheral Blood Predict Hematogenous Recurrence After Resection in Patients with Esophageal Cancer. Ann. Surg. Oncol. 2010, 17, 2779-2786. [CrossRef] [PubMed]

93. Yin, X.-D.; Yuan, X.; Xue, J.-J.; Wang, R.; Zhang, Z.-R.; Tong, J.-D. Clinical significance of carcinoembryonic antigen-, cytokeratin 19-, or survivin-positive circulating tumor cells in the peripheral blood of esophageal squamous cell carcinoma patients treated with radiotherapy. Dis. Esophagus 2012, 25, 750-756. [CrossRef]

94. Honma, H.; Kanda, T.; Ito, H.; Wakai, T.; Nakagawa, S.; Ohashi, M.; Koyama, Y.; Valera, V.A.; Akazawa, K.; Hatakeyama, K. Squamous cell carcinoma-antigen messenger RNA level in peripheral blood predicts recurrence after resection in patients with esophageal squamous cell carcinoma. Surgery 2006, 139, 678-685. [CrossRef] [PubMed]

95. Hsieh, C.-C.; Hsu, H.-S.; Chang, S.-C.; Chen, Y.-J. Circulating Cell-Free DNA Levels Could Predict Oncological Outcomes of Patients Undergoing Esophagectomy for Esophageal Squamous Cell Carcinoma. Int. J. Mol. Sci. 2016, 17, 2131. [CrossRef] [PubMed]

96. Diakowska, D.; Nienartowicz, M.; Grabowski, K.; Rosińczuk, J.; Krzystek-Korpacka, M. Toll-like receptors TLR-2, TLR-4, TLR-7, and TLR-9 in tumor tissue and serum of the patients with esophageal squamous cell carcinoma and gastro-esophageal junction cancer. Adv. Clin. Exp. Med. 2018, 28, 515-522. [CrossRef]

97. Liao, Y.; Xing, S.; Xu, B.; Liu, W.; Zhang, G. Evaluation of the circulating level of fibroblast activation protein $\alpha$ for diagnosis of esophageal squamous cell carcinoma. Oncotarget 2017, 8, 30050-30062. [CrossRef]

98. Laird, P.W. The power and the promise of DNA methylation markers. Nat. Rev. Cancer 2003, 3, $253-266$. [CrossRef]

99. Duffy, M.J.; Napieralski, R.; Martens, J.; Span, P.N.; Spyratos, F.; Sweep, F.C.; Brünner, N.; Foekens, J.; Schmitt, M. Methylated genes as new cancer biomarkers. Eur. J. Cancer 2009, 45, 335-346. [CrossRef]

100. Roy, D.; Tiirikainen, M. Diagnostic Power of DNA Methylation Classifiers for Early Detection of Cancer. Trends Cancer 2020, 6, 78-81. [CrossRef]

101. Zhu, Y.; Zhang, H.; Chen, N.; Hao, J.; Jin, H.; Ma, X. Diagnostic value of various liquid biopsy methods for pancreatic cancer. Med. Baltim. 2020, 99, e18581. [CrossRef]

102. Jin, X.; Cai, C.; Qiu, Y. Diagnostic Value of Circulating microRNAs in Hepatitis B Virus-Related Hepatocellular Carcinoma: A Systematic Review and Meta-Analysis. J. Cancer 2019, 10, 4754-4764. [CrossRef]

103. Cheng, X.; Zhang, L.; Chen, Y.; Qing, C. Circulating cell-free DNA and circulating tumor cells, the "liquid biopsies" in ovarian cancer. J. Ovarian Res. 2017, 10, 75. [CrossRef] [PubMed]

104. Danese, E.; Montagnana, M.; Lippi, G. Circulating molecular biomarkers for screening or early diagnosis of colorectal cancer: Which is ready for prime time? Ann. Transl. Med. 2019, 7, 610. [CrossRef] [PubMed]

105. Umer, M.; Vaidyanathan, R.; Nguyen, N.-T.; Shiddiky, M.J.A. Circulating tumor microemboli: Progress in molecular understanding and enrichment technologies. Biotechnol. Adv. 2018, 36, 1367-1389. [CrossRef] [PubMed]

106. Alix-Panabières, C.; Bartkowiak, K.; Pantel, K. Functional studies on circulating and disseminated tumor cells in carcinoma patients. Mol. Oncol. 2016, 10, 443-449. [CrossRef] [PubMed]

107. Kanda, Y. Investigation of the freely available easy-to-use software 'EZR' for medical statistics. Bone Marrow Transplant. 2012, 48, 452-458. [CrossRef]

Publisher's Note: MDPI stays neutral with regard to jurisdictional claims in published maps and institutional affiliations.

(C) 2020 by the authors. Licensee MDPI, Basel, Switzerland. This article is an open access article distributed under the terms and conditions of the Creative Commons Attribution (CC BY) license (http://creativecommons.org/licenses/by/4.0/). 